\title{
Protein Tyrosine Phosphatase $\delta$ Mediates the Sema3A-Induced Cortical Basal Dendritic Arborization through the Activation of Fyn Tyrosine Kinase
}

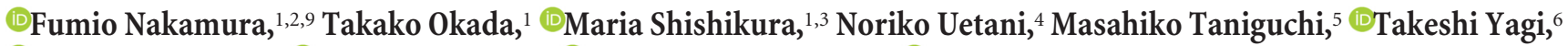

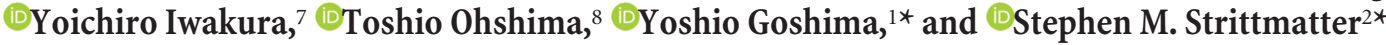 \\ ${ }^{1}$ Department of Molecular Pharmacology and Neurobiology, Graduate School of Medicine, Yokohama City University, Yokohama, Kanagawa 236-0004, \\ Japan, ${ }^{2}$ Departments of Neurology and of Neuroscience, Yale University School of Medicine, New Haven, Connecticut 06536, ${ }^{3}$ Department of Neuroscience, \\ Johns Hopkins University, Baltimore, Maryland 21218, ${ }^{4}$ Goodman Cancer Centre, McGill University, Montreal, Quebec, H3G 1Y6, Canada, ${ }^{5}$ Department of \\ Biochemistry, Cancer Research Institute, Sapporo Medical University, Sapporo 060-8556, Japan, ${ }^{6}$ KOKORO-Biology Group, Laboratories for Integrated \\ Biology, Graduate School of Frontier Biosciences, Osaka University, Suita, Osaka 565-0871, Japan, ${ }^{7}$ Division of Experimental Animal Immunology, Research \\ Institute for Biomedical Science, Tokyo University of Science, Noda, Chiba 278-0022, Japan, ${ }^{8}$ Laboratory for Molecular Brain Science, Department of Life \\ Science and Medical Bio-science, Waseda University, Tokyo, 162-8480, Japan, and 'Department of Biochemistry, School of Medicine, Tokyo Women's \\ Medical University, Tokyo, 162-8666, Japan
}

Leukocyte common antigen-related (LAR) class protein tyrosine phosphatases (PTPs) are critical for axonal guidance; however, their relation to specific guidance cues is poorly defined. We here show that PTP-3, a LAR homolog in Caenorhabditis elegans, is involved in axon guidance regulated by Semaphorin-2A-signaling. PTP $\delta$, one of the vertebrate LAR class PTPs, participates in the Semaphorin-3A (Sema3A)-induced growth cone collapse response of primary cultured dorsal root ganglion neurons from Mus musculus embryos. In vivo, however, the contribution of PTP $\delta$ in Sema3A-regualted axon guidance was minimal. Instead, PTP $\delta$ played a major role in Sema3A-dependent cortical dendritic growth. $P t p \delta^{-I-}$ and Sema $3 a^{-1-}$ mutant mice exhibited poor arborization of basal dendrites of cortical layer $\mathrm{V}$ neurons. This phenotype was observed in both male and female mutants. The double-heterozygous mutants, $P \operatorname{tp} \delta^{+/-} ; \operatorname{Sema} 3 a^{+/-}$, also showed a similar phenotype, indicating the geneticinteraction. In $P t p \delta^{-1-}$ brains, Fyn and Srckinases were hyperphosphorylated at their C-terminal Tyr527 residues. Sema3A-stimulation induced dephosphorylation of Tyr527 in the dendrites of wild-type cortical neurons but not of $P \operatorname{tp} \delta^{-1-}$. Arborization of cortical basal dendrites was reduced in $\mathrm{Fyn}^{-1-}$ as well as in $\mathrm{Ptp}_{\mathrm{\delta}} \boldsymbol{\delta}^{+/} ; \mathrm{Fyn}^{+/-}$double-heterozygous mutants. Collectively, PTP $\delta$ mediates Sema3A-signaling through the activation of Fyn by $\mathrm{C}$-terminal dephosphorylation.

Key words: C. elegans; dendritic growth; Fyn; LAR; PTP-3; PTP $\delta$ PTPRD; pyramidal neuron; Sema2A; Sema3A

Significance Statement

The relation of leukocyte common antigen-related (LAR) class protein tyrosine phosphatases (PTPs) and specific axon guidance cues is poorly defined. We show that PTP-3, a LAR homolog in Caenorhabditis elegans, participates in Sema2A-regulated axon guidance. PTP $\delta$, a member of vertebrate LAR class PTPs, is involved in Sema3A-regulated cortical dendritic growth. In Sema3A signaling, PTP $\delta$ activates Fyn and Src kinases by dephosphorylating their C-terminal Tyr residues. This is the first evidence showing that LAR class PTPs participate in Semaphorin signaling in vivo.

\section{Introduction}

Semaphorins are a family of axon guidance molecules that regulate the axonal projection of specific neurons in both invertebrates and vertebrates (Raper, 2000; Pasterkamp, 2012; Worzfeld and Offermanns, 2014). Semaphorins are divided into seven classes based on their species and primary structures (Semaphorin Nomenclature Committee, 1999). Semaphorin-2A (Sema2A) is a class 2 invertebrate secreted Semaphorin, which repulsively regulates the 
projection of motoneurons to target muscles in Drosophila (Matthes et al., 1995; Winberg et al., 1998). Semaphorin-3A (Sema3A), a prototype of class 3 vertebrate secreted Semaphorins, repels the axons from dorsal root ganglion (DRG) and hippocampal neurons (Raper, 2000). Sema3A also regulates the dendritic development of cortical and hippocampal pyramidal neurons (Fenstermaker et al., 2004; Nakamura et al., 2009; Valnegri et al., 2015).

Plexins have been identified as principal receptors for Semaphorins (Tamagnone et al., 1999). In Caenorhabditis elegans, Plexin-2 serves as a specific receptor for Sema2A (Nakao et al., 2007). We have reported that Sema2A-Plexin-2 signaling regulates the axon guidance of $\mathrm{DD} / \mathrm{VD}$ motoneurons in nematodes (Nakamura et al., 2014). In vertebrates, Sema3A uses Neuropilin-1 (NRP1) as the primary receptor (Worzfeld and Offermanns, 2014). Plexin-A forms a hetero-complex with NRP1 and acts as a signal transducer of repulsive response of Sema3A (Takahashi et al., 1999). This complex also regulates Sema3A-induced dendritic morphogenesis of cortical layer $\mathrm{V}$ pyramidal neurons (Valnegri et al., 2015). Both mutant mice of $N p n-1^{\text {sema- }}$, which express a mutant NRP1 abolished Sema3A binding, and Plexin-A4 ${ }^{-1-}$ exhibit less elaborate basal dendrites (Gu et al., 2003; Tran et al., 2009). NRP1 also interacts with neural adhesion molecule L1 to mediate Sema3A-signaling in the projection of corticospinal tract (Castellani et al., 2000). It has been shown that Fyn tyrosine kinase is involved in the Sema3Aregulated dendritic branching and spine maturation of cortical pyramidal neurons (Morita et al., 2006). However, its activation mechanism has yet to be revealed.

Leukocyte common antigen-related (LAR) class protein tyrosine phosphatases (PTPs) have been implicated as signaling molecules of axon guidance and synapse formation (Chagnon et al., 2004; Takahashi and Craig, 2013; Um and Ko, 2013; Stoker, 2015). In C. elegans, LAR homolog PTP-3 is involved in the commissural projection and dorsal fasciculation of $\mathrm{DD} / \mathrm{VD}$ motor neurons (Ackley et al., 2005). Drosophila LAR participates in the innervation of ISNb motoneurons to ventral muscles and laminarspecific targeting of photoreceptor R7 neurons (Ensslen-Craig and Brady-Kalnay, 2004). Heparan sulfate proteoglycans, Syndecan and Dally-like, bind Drosophila LAR and participate in motor axonguidance and synaptic development (Fox and Zinn, 2005; Johnson et al., 2006).

In vertebrates, LAR class PTPs consist of three members: LAR, $\operatorname{PTP} \delta$, and PTP $\sigma$. LAR acts as a receptor for heparan-sulfate proteoglycans and guides peripheral sensory axons to the skin in zebrafish (Wang et al., 2012). Chick PTP $\sigma$ interacts with heparan sulfate proteoglycans in retinal basal membrane (Aricescu et al., 2002). PTP $\sigma$ may modulate retinal axon growth and guidance in visual system (Ledig et al., 1999; Johnson et al., 2001; Rashid-

Science and Technology (MEXT) of Japan to Y.G.; the fund for Creation of Innovation Centers for Advanced Interdisciplinary Research Areas Program in the Project for Developing Innovation Systems from MEXT to Y.G.; and the National Institutes of Health to S.M.S. We thank Caenorhabditis Genetic Center, which is funded by NHI Office of Research Infrastructure Programs (P40 0D010440), for providing mab-20(bx61), plx-2(ev775), ptp-3(op 147) and ptp-3(ok244);ptp-3(ok244) was kindly provided by the C. elegans Gene Knock-out Project at the Oklahoma Medical Research Foundation, which is a part of the international C. elegans Gene Knock-out Consortium; Shin Takagi and B. D. Ackley for providing $p / x-2(t m 729)$ and various expression constructs; Michel Streuli for providing human LAR and PTP $\delta$ expression vectors; Kazuya Mizuno for providing anti-PTP $\delta$ ectodomain rabbit antibodies; Joshua Sanes for providing GFP-M mice; Toshifumi Takahashi, Kashiko Tachikawa, and Oumi Nakajima for their excellent technical assistance; and Lisa Bond and Motokazu Koga for critical reading of the paper.

*Y.G. and S.M.S. contributed equally to this work.

The authors declare no competing financial interests.

Correspondence should be addressed to either of the following: Fumio Nakamura, Tokyo Women's Medical University, 8-1 Kawada-chou, Shinjuku-ku, Tokyo, 162-8666, Japan, E-mail:f-nakamura@umin.ac.jp; or Stephen M. Strittmatter, Yale University School of Medicine, 295 Congress Avenue, New Haven, CT 06536, E-mail: stephen.strittmatter@yale.edu.

DOI:10.1523/JNEUROSCI.2519-16.2017

Copyright $\odot 2017$ the authors $\quad 0270-6474 / 17 / 377126-15 \$ 15.00 / 0$
Doubell et al., 2002). In addition, LAR and PTP $\sigma$ bind chondroitin sulfate proteoglycans to inhibit neurite outgrowth of CNS neurons (Shen et al., 2009; Fisher et al., 2011). PTP $\delta$ may participate in the projection of motor axons (Stepanek et al., 2005) as well as in the dendritic growth of olfactory mitral cells (Shishikura et al., 2016). PTP $\delta$ is also involved in spatial learning (Uetani et al., 2000). In terms of synapse formation, specific ligands for LAR class PTPs, such as IL-1 receptor accessory protein-like 1 (IL1RAPL1) and Slitrk, have been identified (Yoshida et al., 2011; Takahashi et al., 2012). In contrast, the relation of LAR class PTPs and particular axon and/or dendrite guidance molecules remains to be defined.

We found that PTP-3, a LAR homolog in C. elegans, participates in Sema2A-regulated axon guidance. Murine PTP $\delta$ is involved in Sema3A-regulated cortical dendritic growth. In Sema3A signaling, PTP $\delta$ activates Fyn and Src kinases by dephosphorylating their C-terminal Tyr residues. The involvement of LAR class PTPs in Semaphorin signaling may be preserved beyond species.

\section{Materials and Methods}

C. elegans strains, cultures, and phenotypic analyses. Bristol strain N2 was used as the standard wild-type strain. mab-20(bx61), plx-2(ev775), ptp3(op147), and ptp-3(ok244) were provided from the Caenorhabditis Genetics Center. plx-2(tm729) was provided by S. Takagi (Nagoya University, Nagoya, Japan). To visualize DD/VD neurons, wild-type and those mutants were intercrossed with oxIs12[unc47::GFP]. Genotyping primers and expected fragment size for each mutant are as follows: plx-2(tm729), tm729-5f ( $5^{\prime}$-gactggaggtggaagatggtgaat- $\left.3^{\prime}\right)$, tm729-wtr (5'-ATCCATCATTGTCGCTGACCCTAA-3'), tm729-3r (5' -caacaaa cggtaggacatctcaca-3'), wild-type (wt) 630 bp, tm729 329 bp; plx2(ev775), plx2-Q1742wt (5'-TCAGCCAACAACGTTTGCCTC-3'), plx2-Q1742stop (5'-TCAGCCAACAACGTTTGCCTt-3'), plx2-ev775r (5'-taaggcgcggattgaggcaag-3'), wt 355 bp, ev775 355 bp; ptp-3(op147), op147-5f ( $5^{\prime}$-ctgttcctgtcgcaataccatct- $\left.3^{\prime}\right)$, op147-3r ( $5^{\prime}$-gcttgatctctcgaacttcaggt- $\left.3^{\prime}\right)$, tc1-rpt ( $5^{\prime}$-agtggatatcttttggccagcact- $\left.3^{\prime}\right)$, wt $650 \mathrm{bp}$, op147 400 bp; ptp-3(ok244), ok244-left ( $5^{\prime}$-tagattgcaaccgacccaaac-3'), ok244-right ( $5^{\prime}$-cttatccggatgcaatccagt- $\left.3^{\prime}\right)$, ok244-wt (5'-ATGGTTTTACCACGCGATGAT-3'), wt 760 bp, ok244 403 bp; $\boldsymbol{m a b}$-20(bx61), mab20-P188wt (5'-TCAGCCAACAACGTTTGCCTC-3'), mab20P188L (5'-GAATCATCTGATCTACCGTCt-3'), mab20-bx61r (5' gccgagccaaaatggcctact-3'), wt 519 bp, bx61 519 bp.

Phenotypic analysis of the DD/VD neuronal projection was described previously (Nakamura et al., 2014). Strong allele mutants ( $p l x-2(t m 729)$, ptp-3(op147), and their double mutant) were cultured at $20^{\circ} \mathrm{C}$. Weak allele mutants (mab-20(bx61), plx-2(ev775), ptp-3(ok244), and their double mutants) were cultured at $25^{\circ} \mathrm{C}$ because mab-20(bx61) is temperature-sensitive. The gap (premature termination) and defasciculation (including premature bifurcation) of the DD/VD dorsal nerve cord were scored as irregular projection. Premature termination of caudal projection of dorsal nerve cord, which does not reach above DD6 cell body, was also treated as gap phenotype. In one assay, 30-40 animals were examined and the penetrance was scored. At least seven independent assays were performed in each strain. Images of $\mathrm{DD} / \mathrm{VD}$ projection were captured through $20 \times$ and $40 \times$ objective lenses equipped with an AxioPlan 2 microscope (Carl Zeiss) and a Spot-2e CCD camera (Spot).

Sema2A-Plexin-2 binding assay. Sema2A-Fc-AP and Plexin-2 expression vectors were provided by S Takagi (Nagoya University, Nagoya, Japan). PTP-3B (PTP-3 short isoform) construct was provided by B.D. Ackley (University of Kansas, Lawrence, Kansas). The coding fragment of PTP-3B without secretion signal was PCR-amplified with ptp3b-66f ( $5^{\prime}$-atcggtaccGTACCATCAGCGCCTCGAAACTTCAAT-3') andptp3bendr ( $5^{\prime}$-atCTACGAGAAATTGTCATAGGCGGCTAGGT-3') primers and cloned into a modified pSecTag2B vector harboring HA epitope. Sema2A-Fc-AP protein was expressed in HEK293 stable cells and the conditioned medium was concentrated. A 24 well plate was coated with $50 \mu \mathrm{g} / \mathrm{ml}$ poly-L-lysine and seeded with $1 \times 10^{6} \mathrm{HEK} 293 \mathrm{~T}$ cells/plate. 
Table 1. Antibodies

\begin{tabular}{|c|c|c|c|}
\hline Antibody (mAb clone) & Company (Catalog \#), RRIDs & Dilution & Application \\
\hline$\beta$-Actin (AC-74), mouse mAb & $\begin{array}{l}\text { Sigma-Aldrich (A5316) } \\
\text { RRID: } A B 476743\end{array}$ & $1: 9000$ & IB \\
\hline Fyn (FYN3), rabbit pAb & $\begin{array}{l}\text { Santa Cruz Biotechnology (sc-16) } \\
\text { RRID: AB_631528 }\end{array}$ & $1: 5000$ & IB \\
\hline HA (C29F4), rabbit mAb & $\begin{array}{l}\text { Cell Signaling Technology (3724) } \\
\text { RRID: AB_1549585 }\end{array}$ & $1: 5000$ & IB \\
\hline D2 domain of LAR class PTP, rabbit pAb & This paper & $1: 100$ & IP from brain \\
\hline LAR, goat pAb & $\begin{array}{l}\text { Santa Cruz Biotechnology (sc-1119) } \\
\text { RRID: AB_631874 }\end{array}$ & $1: 400$ with Canget $A$ & ICC (DRG) \\
\hline LAR, mouse mAb & BD Biosciences (610351) RRID: AB_397741 & $1: 3000$ & IB (IP from brain) \\
\hline MAP2, chick pAb & $\begin{array}{l}\text { Abcam (ab5392) } \\
\text { RRID: AB_2138153 }\end{array}$ & 1:5000 & ICC (cortical neuron) \\
\hline MAP2 (AP-2), mouse mAb & $\begin{array}{l}\text { Sigma-Aldrich (M1406) } \\
\text { RRID:AB_477171 }\end{array}$ & $1: 3000$ & ICC (cortical neuron) \\
\hline Myc (9E10), mouse mAb & $\begin{array}{l}\text { Sigma-Aldrich (M4439) } \\
\text { RRID:AB_439694 }\end{array}$ & $\begin{array}{l}1: 2000 \\
1: 1000\end{array}$ & $\begin{array}{l}\text { IB } \\
\text { ICC (DRG) }\end{array}$ \\
\hline Neuropilin-1 (D62C6), rabbit mAb & $\begin{array}{l}\text { Cell Signaling Technology (3725) } \\
\text { RRID: AB_2155231 }\end{array}$ & $1: 12,000$ & IB \\
\hline Plexin-A4 (C5D1), rabbit mAb & $\begin{array}{l}\text { Cell Signaling Technology (3816) } \\
\text { RRID: AB_2166410 }\end{array}$ & $1: 6000$ & IB \\
\hline PTP $\delta$ (F34a6), rat mAb conditioned medium & Shishikura et al., 2016 & $\begin{array}{l}1: 25 \\
1: 500 \\
1: 500\end{array}$ & $\begin{array}{l}\text { IB } \\
\text { IHC (brain coronal section) } \\
\text { ICC (cortical neuron) }\end{array}$ \\
\hline PTP $\delta$, rabbit pAb & Mizuno et al., 1993 & 1:500 with Canget $A$ & ICC (DRG) \\
\hline $\operatorname{PTP} \sigma(17 G 7.2)$, mouse mAb & $\begin{array}{l}\text { MédiMabs (MM-0020) } \\
\text { RRID: AB_1808357 }\end{array}$ & $\begin{array}{l}\text { 1:5000 } \\
1: 3000 \\
\text { 1:50 with Canget A }\end{array}$ & $\begin{array}{l}\text { IB (COS-7) } \\
\text { IB (IP from brain) } \\
\text { ICC (DRG) }\end{array}$ \\
\hline $\operatorname{Src}(32 G 6)$, rabbit mAb & $\begin{array}{l}\text { Cell Signaling Technology }(9935,2123) \\
\text { RRID: AB_2106047 }\end{array}$ & $1: 5000$ & $\mathrm{IB}$ \\
\hline Src (GD11), mouse mAb & $\begin{array}{l}\text { Millipore (05-184) } \\
\text { RRID: AB_2302631 }\end{array}$ & 1:1000 with Canget $A$ & ICC (DRG, cortical neuron) \\
\hline pY416 Src (D49G4), rabbit mAb & Cell Signaling Technology $(9935,6943)$ RRID: AB_10860245 & $1: 5000$ & IB \\
\hline pY527 Src, rabbit pAb & Cell Signaling Technology $(9935,2105)$ RRID: AB_10829463 & $\begin{array}{l}\text { 1:5000 } \\
\text { 1:1000 with Canget A }\end{array}$ & $\begin{array}{l}\text { IB } \\
\text { ICC (DRG, cortical neuron) }\end{array}$ \\
\hline$\alpha$-tubulin (DM1A), mouse mAb & $\begin{array}{l}\text { Sigma-Aldrich (T9026) } \\
\text { RRID:AB_477593 }\end{array}$ & $1: 5000$ & IB \\
\hline Phosphotyrosine (4G10), mouse mAb & $\begin{array}{l}\text { Millipore }(05-321) \\
\text { RRID: AB_309678 }\end{array}$ & $1: 2000$ & IB \\
\hline V5, mouse mAb & $\begin{array}{l}\text { Invitrogen (R960-25) } \\
\text { RRID: AB_2556564 }\end{array}$ & $\begin{array}{l}1: 10,000 \\
1: 2500\end{array}$ & $\begin{array}{l}\text { IB } \\
\text { ICC }\end{array}$ \\
\hline Secondary antibodies & & & \\
\hline $\begin{array}{l}\text { AlexaFluor 488-, 594-, 647- labeled anti-mouse, rabbit, or chick } \\
\text { AlexaFluor 488-labeled streptavidin }\end{array}$ & $\begin{array}{l}\text { Invitrogen (A-11029, A11037, A-21244, etc) } \\
\text { Invitrogen (S32354) }\end{array}$ & $\begin{array}{l}1: 1000 \sim 1: 2000 \\
1: 1000\end{array}$ & $\begin{array}{l}\text { ICC } \\
\text { ICC (cortical neuron) }\end{array}$ \\
\hline Alexa488-labeled Phalloidin & Invitrogen (A12379) & 1:1000 & ICC \\
\hline Biotin-conjugated anti-rat & Invitrogen (31830) & $1: 2000$ & ICC (cortical neuron) \\
\hline HRP-conjugated anti-mouse or rabbit & GE (NA931V, NA934V) & $1: 10,000$ & IB \\
\hline HRP-conjugated anti-rat & Millipore (AP183P) & $1: 5000$ & IB \\
\hline HRP-conjugated streptavidin & Perkin-Elmer (NEL700A001KT) & $1: 500$ & ICC (cortical neuron) \\
\hline
\end{tabular}

IB, Immunoblotting; ICC, immunocytochemistry; IHC, immunohistochemistry; IP, immunoprecipitation; RRIDs, Research Resource Identifiers.

The cells were transfected with mock-vector, Myc-Plexin-2, HA-PTP$3 \mathrm{~B}$, or both. After $2 \mathrm{~d}$ of incubation, the cells were incubated with diluted Sema2A-Fc-AP (0-10 nM) on ice for $2 \mathrm{~h}$. Each well was washed with Hanks balanced buffer supplemented with 20 mM HEPES NaOH, pH 7.0, and $0.05 \%$ BSA five times, fixed with the mixture of $20 \mathrm{~mm}$ HEPES $\mathrm{NaOH}$, $\mathrm{pH} 7.0,150 \mathrm{~mm} \mathrm{NaCl}$, and 3.7\% formaldehyde at RT for $10 \mathrm{~min}$, and headinactivated at $67^{\circ} \mathrm{C}$ for $2 \mathrm{~h}$ in the presence of Hanks balanced buffer supplemented with 20 mM HEPES NaOH, pH7.0. Bound AP-probe was monitored by enzymatic hydrolysis of para-nitrophenylphosphate (pNPP). Each well was given $250 \mu$ l of pNPP solution (Sigma-Aldrich, N1891) and the plate was incubated at RT for $1 \mathrm{~d}$. Yellow-colored solution was collected, centrifuged, and measured $\mathrm{OD}_{405}$ with a 96 -well plate reader. Specific binding was obtained by subtracting the absorbance of mock-vector (nonspecific binding) from other conditions.

Antibodies. The antibodies used in this study and their dilutions are listed in Table 1. Anti-LAR class PTP polyclonal rabbit antibody was raised against human PTP $\delta$ D2 domain (1620-1912 AA) and affinitypurified through GST-mouse PTP $\delta$ D2 column. Anti-PTP $\delta$ ectodomain rabbit polyclonal antibody was provided by K. Mizuno (Tokyo Metropolitan Institute for Neuroscience, Tokyo, Japan). Anti-PTP $\delta$ ectodomain (FNIII-2, 3, 8) rat monoclonal antibody (F34a6) was described previously (Shishikura et al., 2016).

In situ hybridization. In situ hybridization of frozen tissue sections with digoxigenin probes was performed as previously described (Nakamura et al., 2009). The following antisense probes were generated using the coding regions of the cDNA indicated in parenthesis: LAR, mouse LAR (26-446 AA); PTP $\delta$, mouse PTP $\delta$ A Isoform (1-341 AA); PTP $\sigma$, mouse PTP $\sigma(1-387$ AA).

Plasmid construction. The coding fragment of human PTP $\delta$ intracellular D2 domain (1620-1912 AA) was amplified with hD-1620f (5' -aaggatccGTGCCAGCTAGAAACTTGTATG- $3^{\prime}$ ) and hD-endr (5' -aactcgagCTACGTTGCATAGTGGTCAAAG-3') primers and cloned into 
pGEX6P1 (GE Healthcare) to generate pGEX6P-hPTP $\delta$-D2. Expression vectors of mouse LAR, PTP $\delta$ (D Isoform), and PTP $\sigma$ were described previously (Shishikura et al., 2016). PTP $\delta$ expression vector was used as a template to construct $\mathrm{PTP} \delta$-D1 $(\mathrm{C} / \mathrm{S})$, a phosphatase-inactive mutant of $\mathrm{PTP} \delta$, where Cys 1149 in the D1 catalytic domain was replaced with Ser using primers $\mathrm{mD}$-D1149Sr (5' -tgagctGTGTACCACCATTGGCCCTGCATC- $3^{\prime}$ ) and mD-D1151f (5'-GCTGGTGTTGGCAGAACTGGCTGCTTC-3'). The coding fragment of mouse PTP $\delta$ wild-type or D1 $(\mathrm{C} / \mathrm{S})$ mutant was transferred to a pHSV vector for the preparation of recombinant herpes simplex viruses. Briefly, 2-2 cells were transfected with one of the constructed pHSV vectors and subsequently infected with IE2 defective herpes-simplex virus (5dl1.2). Mock virus was prepared with the $\mathrm{pHSV}$ vector without any insertion. All constructs were confirmed by DNA sequencing.

Mutant mice. Sema3a (RRID:MGI:3832572; Taniguchi et al., 1997; Nakamura et al., 2009), Ptp $\delta$ (RRID:MGI:3056784; Uetani et al., 2000; Shishikura et al., 2016), and Fyn (RRID:MGI:2175035; Morita et al., 2006) mutant mice were housed on a $12 \mathrm{~h}$ light/dark cycle in the animal facility at Yokohama City University Graduate School of Medicine. These mice were fed an autoclaved diet and given water. The mutant mice were maintained as heterozygous on a C57BL/6 background. Homozygous or double-heterozygous mutant mice were obtained by intercrossing the same or different heterozygous mice. Genotyping was determined as described previously (Morita et al., 2006; Nakamura et al., 2009; Shishikura et al., 2016). GFP-M genotype was introduced to the mutant mice by intercrossing with thy1-GFP-m (MGI:4941461; Feng et al., 2000). Integration of GFP-M was confirmed by genotype PCR with gfp-5f (5'-AAGTTCATCTGCACCACCG-3') and gfp-3r (5'-TCCTTGAAGAAGATGGTGCG-3') primers. All procedures were performed according to the guidelines outlined in the Institutional Animal Care and Use Committee of the Yokohama City University School of Medicine. The mouse experiments were approved by the committee with the protocol No. "F-A-14-047". Throughout the experimental procedures, all efforts were made to minimize the number of animals used and their suffering.

Immunoblot analysis. Sex of analyzed mice are as follows: wild-type, three females; $P t p \delta^{-1-}$, one male, two females. Mice (1 month) were killed with deep anesthetization with diethyl ether. Dissected brains were immediately frozen in liquid $\mathrm{N}_{2}$ and stored at $-80^{\circ} \mathrm{C}$. Each brain (cerebrum to oblongata) was homogenized in $5 \mathrm{ml}$ of homogenization buffer (50 mм HEPES NaOH, pH7.4, $150 \mathrm{~mm} \mathrm{NaCl}, 1 \mathrm{~mm}$ EDTA, $1 \mathrm{~mm}$ $\mathrm{Na}_{3} \mathrm{VO}_{4}, 10 \%$ glycerol, 1000 -fold diluted protease inhibitor cocktail (Sigma-Aldrich, $\mathrm{P} 8340$ ), and $5 \mathrm{~mm} \mathrm{CH}_{3} \mathrm{COOI}$ ). The samples were placed on ice for $30 \mathrm{~min}$, supplemented with $1 \mathrm{~mm} \mathrm{DTT}$, and stored at $-80^{\circ} \mathrm{C}$ until use. The homogenates $(500 \mu \mathrm{g})$ were suspended in $500 \mu \mathrm{l}$ of RIPA buffer (20 mm Tris HCl, pH7.4, $150 \mathrm{~mm} \mathrm{NaCl}, 5 \mathrm{~mm}$ EDTA, $0.5 \mathrm{~mm}$ $\mathrm{Na}_{3} \mathrm{VO}_{4}, 10 \%$ Glycerol, $1 \%$ Triton X-100, 0.25\% deoxycholate, $0.1 \%$ SDS, and protease inhibitors) and centrifuged. The solubilized fractions (20 $\mu \mathrm{g}$, each sample) were subjected to immunoblot analyses with various antibodies listed in Table 1.

Immunoprecipitation. HEK293T cells were cotransfected with $\mathrm{PTP} \delta$ Myc and HA-NRP1 or HA-Plexin-A1. After $2 \mathrm{~d}$ of incubation, cells were lysed with IP150 buffer (20 mm Tris $\mathrm{HCl}, \mathrm{pH} 7.4,150 \mathrm{~mm} \mathrm{NaCl}, 5 \mathrm{~mm}$ EDTA, $1 \mathrm{~mm} \mathrm{NaF}, 0.5 \mathrm{~mm} \mathrm{Na} \mathrm{VO}_{4}, 1 \%$ Triton X-100, protease inhibitors) and centrifuged. The solubilized fractions were mixed with anti-cMyc agarose at $4^{\circ} \mathrm{C}$ O/N. The beads were washed with IP150 buffer and analyzed on immunoblots with anti-HA (1:5000) and anti-Myc (1:2000). For immunoprecipitation of HA-tagged proteins, anti-HA beads (Roche, 11815016001 ) were used. Mouse brains from P0 were homogenized in the homogenization buffer. After removing the nuclei fraction by low speed centrifugation $(500 \times g)$, the supernatant was ultracentrifuged at $100,000 \times g$ for $60 \mathrm{~min}$. The pellet was suspended in the lysis buffer (20 mm HEPES NaOH, pH 7.4, $50 \mathrm{~mm} \mathrm{NaCl,} \mathrm{0.5 \%} \mathrm{Triton}$ $\mathrm{X}-100$, protease inhibitors) and the solubilized fraction was separated by centrifugation. The fraction $(200 \mu \mathrm{l}, \sim 1 \mathrm{mg})$ was mixed with $300 \mu \mathrm{l}$ of IP150 buffer, precleared with protein-A agarose beads $(10 \mu \mathrm{l})$ for $2 \mathrm{~h}$ at $4^{\circ} \mathrm{C}$, then mixed with $5 \mu \mathrm{g}$ of anti-LAR class PTP rabbit IgG or preimmune $\operatorname{IgG}$ for $\mathrm{O} / \mathrm{N}$ at $4^{\circ} \mathrm{C}$. The immune complex was recovered with the addition of protein-A agarose beads $(5 \mu \mathrm{l})$. The beads were extensively washed with IP150 buffer and analyzed on immunoblots with
anti-NRP1 (1:12,000), anti-Plexin-A4 (1:6000), anti-LAR (1:3000), antiPTP $\delta(\mathrm{F} 34 \mathrm{a} 6,1: 25)$, and anti-PTP $\sigma(1: 3000)$.

Primary culture of DRG neurons. Eight-well glass chambers $\left({ }^{*} 154534\right.$, Nunc) were coated with poly-L-lysine $(100 \mu \mathrm{g} / \mathrm{ml})$ and laminin $(8 \mu \mathrm{g} /$ $\mathrm{ml})$. Dissected DRG explants from wild-type or Ptp $\delta$ mutant embryos (E16-E18) were incubated in the mouse DRG medium (neurobasal medium supplemented with 2\% B27, 1 mm GlutaMax, and $10 \mathrm{ng} / \mathrm{ml} \mathrm{NGF)}$ at $37^{\circ} \mathrm{C}$ for $1 \mathrm{~d}$. In some experiments, transfection of siRNA or infection of recombinant HSV was performed and incubated further by $1-2 \mathrm{~d}$. The explants were stimulated with AP-Sema3A (Takahashi et al., 1999) for 5-30 min and fixed with either PBS pH 7.4 containing 2\% formaldehyde and $10 \%$ sucrose for collapse assay or PBS supplemented with $2 \%$ paraformaldehyde (PFA) for immunocytochemistry.

siRNA transfection. Three different siRNAs against mouse PTP $\delta$ and $P T P \sigma$ were synthesized and purchased from Integrated DNA Technologies. The sequences are available upon request. Mouse LAR siRNA mixture (sc-35794) was purchased from Santa Cruz Biotechnology. These siRNAs suppressed the targeted-PTP expression in COS-7 cells (see Fig. $2 \mathrm{Ba}$ ). Weak off-target effects of these siRNAs within the LAR family were also observed. Transfection of the siRNA mixture into mouse wild-type DRG explant was performed with DharmaFECT-3 (Thermo Scientific). In brief, $140 \mathrm{pmol}$ of siRNA was mixed with $6 \mu \mathrm{l}$ of the transfection reagent in $220 \mu \mathrm{l}$ of Neurobasal medium. The aliquot of the mixture (25 $\mu \mathrm{l})$ was added to one well $(250 \mu \mathrm{l})$ containing a DRG explant. After $4 \mathrm{~h}$ incubation at $37^{\circ} \mathrm{C}$, the medium was replaced with the fresh mouse DRG medium. The DRG explants were further incubated for $2 \mathrm{~d}$ and stimulated with AP-Sema3A for 25 min. The knockdown of protein expression in DRG was confirmed by immunocytochemistry (Fig. $2 B b-B d$ ).

Rescue study. After $1 \mathrm{~d}$ incubation of the DRG explants from Ptp $\delta$ mutant embryos, HSV-PTP $\delta$-V5 or HSV-PTP $\delta$-D1(C/S)-V5 were infected and incubated for an additional day. The explants were stimulated with AP-Sema3A (0.05-0.3 nM) for $25 \mathrm{~min}$. Growth cone collapse was scored. The expression of exogenous PTP $\delta$ was confirmed by anti-V5 immunocytochemistry (data not shown).

Growth cone collapse assay. Fixed explants were stained with AlexaFluor 488-conjugated phalloidin (1:500 dilution). Fluorescently labeled growth cone morphology was examined through $20 \times$ (for DRG axons) or $40 \times$ (for entorhinal axons) objective lenses and scored either collapsed (without lamellipodium and less than three filopodia) or noncollapsed (with lamellipodia or $>2$ filopodia). In one assay, 50-180 growth cones of each explant were scored. The $n$ values in the figure legends indicate the number of explants in one condition. In each condition, 8-26 explants were examined. Growth cone morphologies were captured through a $40 \times$ objective lens with an Olympus IX-70 inverted microscope and a CCD camera.

DiI trace of entorhino-hippocampal projection. Brains were dissected from $\mathrm{P} 0-\mathrm{P} 2$ newborn mice and fixed with $4 \% \mathrm{PFA} / \mathrm{PBS}$ at $4^{\circ} \mathrm{C}$ for 1 week. Each brain was injected a small DiI crystal to the entorhinal cortex area and incubated at $37^{\circ} \mathrm{C}$ for $14-28 \mathrm{~d}$ in the presence of $4 \%$ PFA/PBS (Supèr and Soriano, 1994; Pozas et al., 2001). The brains were embedded in the $3 \%$ agarose/PBS and sliced in sequential horizontal sections $(100 \mu \mathrm{m})$ with a MicroSlicer (Dosaka EM). The sections were counter-stained with $3 \mu \mathrm{M}$ bisbenzimide to visualize the hippocampal layers and mounted to slide glass. The trace was recorded with a CCD Camera through X10 object lens. Projection of DiI-labeled entorhinal axons in stratum radiatum (sr) was scored as irregular projection. The following genotypes and animals were examined: wild-type, $16 ; P t p \delta^{+/-}, 10 ; P t p \delta^{-1-}, 9$; Sema3a ${ }^{+/-}, 14$; Sema3a $a^{-/-}, 5$; and $P t p \delta^{+/-}$; Sema3a ${ }^{+/-}, 9$. The "overprojection" phenotype in $P t p \delta^{-1-}$ was scored as follows. The width of DiI-labeled hippocampal alveus was measured at the middle of CA1 in the horizontal section, which showed the largest width in a series of sequential sections from each brain. Nine animals of each genotype (wild-type and $P t p \delta^{-1-}$ ) were examined. The average of wild-type width was normalized to $100 \%$.

Morphological analysis of cortical basal dendrites. Sex of analyzed mutant mice are as follows: wild-type, 1 male, 2 females; $P t p \delta^{+/-}, 3$ males, 2 females; Ptp $\delta^{-1-}, 1$ male, 2 females; Sema $3 a^{+/-}, 3$ females; Sema $3 a^{-1-}$, 1 male, 1 female; $\operatorname{Ptp}^{+/-}$; Sema3a ${ }^{+/-}, 3$ females; $\mathrm{Fyn}^{+/-}, 2$ males;

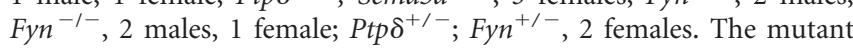


mice introduced GFP-M genotype (1 month) were killed using diethyl ether and transcardially injected $10 \mathrm{ml} 4 \%$ PFA/PBS. Brains were surgically removed, fixed with $4 \% \mathrm{PFA} / \mathrm{PBS}$ at $4^{\circ} \mathrm{C} \mathrm{O} / \mathrm{N}$, and embedded in $3 \%$ agarose/PBS. Coronal sections $(100 \mu \mathrm{m})$ were sliced from the specimens using a MicroSlicer and collected in PBS. The sections were mounted on a slide glass with Fluoromount. Using a Zeiss LSM-510 confocal microscopy, images of basal dendrites from GFP-labeled pyramidal neurons in the cortical layer $\mathrm{V}$ of motor to sensory areas were taken through a $20 \times$ objective lens. For each genotype, 20-31 neurons were selected from two to three independent mouse brains. The basal dendrites of the neurons were traced $>100 \mu \mathrm{m}$ from the center of the cell body with the aid of Fiji, an ImageJ derivative. In each traced neuron, the elaboration of basal dendrites by Sholl analysis (Sholl, 1953) and the total length of the dendrites were examined with Fiji.

Src and pY527-Src immunocytochemistry. DRG explants from Ptp $\delta$ mutant embryos (E16-E17) were stimulated with $0.1 \mathrm{~nm}$ AP-Sema3A for 5-30 min. The explants were fixed with PBS containing 2\% PFA and 10\% sucrose for $1 \mathrm{~h}$, then rinsed twice with Tris-buffered saline ( $25 \mathrm{~mm}$ Tris $\mathrm{HCl}$, pH7.4, $137 \mathrm{~mm} \mathrm{NaCl}, 2.68 \mathrm{~mm} \mathrm{KCl}$ ) supplemented with $0.1 \%$ Triton X100 (TBST). After blocking with TBST 5\% normal goat serum (NGS) for $4 \mathrm{~h}$, the explants were exposed to anti-pY527-Src rabbit pAb (1:1000) and anti-Src mouse mAb (1:667) diluted with Can Get Signal A (NKB-501, Toyobo) at $4^{\circ} \mathrm{C} \mathrm{O} / \mathrm{N}$. The explants were rinsed with TBST three times and subsequently exposed to anti-rabbit IgG-conjugated AlexaFluor 488 (1:1000) and anti-mouse IgG-conjugated AlexaFluor 594 (1:1000) diluted with TBST $1 \%$ NGS at $4^{\circ} \mathrm{C}$ O/N. The explants were washed with TBST for five times and were mounted coverslip with Fluoromount. Confocal images of growth cones were taken through a $63 \times$ objective lens with Zeiss LSM-510 microscopy. Captured images were analyzed with ImageJ. In each condition, 24-30 growth cones were selected, the boundary of each growth cone was manually traced, and the intensity of the selected area was scored. The ratio of pY527 and Src (pY527/Src) in nonstimulated growth cones was treated as $100 \%$. The average of relative ratio from five independent experiments was statistically analyzed.

Primary culture and immunocytochemistry of cortical neurons. Cortical neurons from wild-type or $P t p \delta^{-1-}$ E14 embryos were plated on glass coverslips coated with poly-L-lysine at a density of $1 \times 10^{4}$ cells/well in a 4-well dish, and grown in Neurobasal medium supplemented with $2 \%$ B27, $1 \mathrm{~mm}$ GlutaMax, 50U/ml penicillin and $50 \mu \mathrm{g} / \mathrm{ml}$ streptomycin for $8 \mathrm{~d}$. The neurons were fixed in 2\% PFA/PBS for $30 \mathrm{~min}$ and rinsed once with PBS. The samples were incubated with PBS and $0.1 \%$ Triton X100 (PBST) containing $0.3 \% \mathrm{H}_{2} \mathrm{O}_{2}$ for $30 \mathrm{~min}$ and subsequently blocked with PBST with 5\% skim milk and 5\% NGS at RT for $1 \mathrm{~h}$. The specimens were incubated with anti-PTP $\delta$ rat $\mathrm{mAb}$ (F34a6, 1:500 dilution) and antiMAP2 chick pAb (1:5000) in TBST $2.5 \%$ NGS for O/N at $4^{\circ} \mathrm{C}$. To enhance PTP $\delta$-immunoreactive signal, tyramide Signal Amplification system (Perkin-Elmer, NEL700A001KT) was used. Briefly, the samples were incubated with biotin-conjugated anti-rat IgG secondary antibody (1:2000) for $1 \mathrm{~h}$, with streptavidin-HRP (1:500) for $50 \mathrm{~min}$, and with diluted tyramide-biotin for $10 \mathrm{~min}$ at RT. The bound probes were visualized with the mixture of AlexaFluor 488-conjugated streptavidin (1: $1000)$ and AlexaFluor 594-goat anti-chick antibody (1:1000) in TBST $2.5 \%$ NGS for $3 \mathrm{~h}$ at RT. Immunostaining of pY527-Src and Src was also performed in the same condition as the DRG explants. In this case, MAP2 was labeled with anti-MAP2 chick pAb $(1: 10,000)$ and anti-chick IgGconjugated with AlexaFluor 647 (1:1000). Confocal images of the immunostained cortical neurons were taken through a $40 \times$ objective lens with Zeiss LSM-510 microscopy. For dendritic growth assay, dissociated cortical cultures were stimulated with Sema3A $(0.3 \mathrm{~nm})$ at 6 DIV for $1 \mathrm{~d}$. Fixed specimens were immunostained with anti-MAP2 mAb (1:3000) and AlexaFluor 488-conjugated anti-mouse IgG (1:3000). Stained images were captured through a $20 \times$ lens and analyzed with the aid of Fiji.

Experimental design and statistical analysis. All experiments were performed with appropriate controls such as mock-transfected cells and wild-type animals. Two-tailed unpaired $t$ test, one-way ANOVA with post hoc Tukey-Kramer test, and Fisher's exact test were used. Unpaired $t$ test was performed with Microsoft Excel Mac, 2011. One-way ANOVA with post hoc Tukey-Kramer test was examined with Excel add-in soft- ware StatCel3 (OMS Publishing). Statistical significance of the post hoc test was given as either ${ }^{\star} p<0.05$ or ${ }^{* *} p<0.01$ due to the specification of the software. Fisher's exact test was performed with $\mathrm{R}$ v3.3.2.

C. elegans studies (Fig. $1 B, C$ ): one-way ANOVA with post hoc test was used. Immunoreactivity of RNAi-treated cells (Fig. 2Be): two-tailed unpaired $t$ test was used. Growth cone collapse assays (Figs. $2 D, 3 A, C, 6 G$ ): unpaired $t$ test was used for the comparison of two groups (Fig. $3 A$ ). One-way ANOVA with post hoc Tukey-Kramer test was used to examine more than two conditions (Figs. 2D, 3C, 6G). Analyses of entorhinohippocampal projection: thickness of hippocampal alveus was examined with unpaired $t$ test. The penetrance of irregular entorhinal projection in mutants was examined with Fisher's exact test (Table 2). The numbers of DiI-traced brains are indicated in the DiI trace of entorhinohippocampal projection section. Sex of these specimens could not be determined because they were newborn mice. Analyses of dendritic length (see Figs. $5 \mathrm{M}, O, 7 \mathrm{G}$ ): one-way ANOVA with post hoc TukeyKramer test was performed. Sema3A-induced pY527 dephosphorylation (see Figs. $6 E, 7 B$ ): the difference of relative pY527/Src ratio between wild-type and $P t p \delta^{-1-}$ was examined with unpaired $t$ test (see Fig. $6 E$ ) or one-way ANOVA (see Fig. 7B). Numbers and sexes of the animals used for dendritic analyses (see Figs. 5M, 7G) are described in the Morphological analysis of cortical basal dendrites section. Note that different animals of $P t p \delta^{+/-}$were examined in Figures $5 M$ and $7 G$. Other numbers and statistical results are described in the figure legends and Results.

\section{Results}

\section{PTP-3, a LAR homolog in C. elegans, is involved in Sema2A-Plexin-2 signaling}

The phenotypic similarity of aberrant $\mathrm{DD} / \mathrm{VD}$ projection in $p t p-3$ (Ackley et al., 2005) and plexin-2 (plx-2) or sema2a (mab-20) mutants (Nakamura et al., 2014) suggests possible involvement of LAR class PTPs in Semaphorin-Plexin signaling. Therefore, we examined the genetic interaction of ptp-3 and plexin-2 in nematodes. Although the defect of DD/VD dorsal nerve cord was $3.57 \pm 0.95 \%$ in wild-type, the irregular projection was increased in $p t p-3(o p 147)(14.5 \pm 3.2 \%)$ and $p l x-2(t m 729)(13.4 \pm 1.9 \%$; Fig. $1 A, B$ ), confirming the earlier reports (Ackley et al., 2005; Nakamura et al., 2014). The double-mutant $p l x-2(t m 729) p t p-$ 3 (op147) showed similar severity in the defect $(13.5 \pm 2.1 \%)$ to single mutants (Fig. $1 A, B$ ). The difference of wild-type and these mutants was statistically significant $\left(F_{(3,28)}=4.66, p=0.0092\right.$, ANOVA). Because $p l x-2(t m 729)$ is a null mutant (Nakao et al., 2007) and ptp-3(op147) is a strong allele due to the deletion of phosphatase domains (Harrington et al., 2002), the absence of genetic augmentation suggests that these two genes may act in the same Sema2A-signaling cascade. Genetic interaction of the weak allele mutants, mab-20(bx61), plx-2(ev775), and ptp-3(ok244), was also examined (Fig. 1C). As mab-20(bx61) is temperaturesensitive, the single and double mutants were cultured at $25^{\circ} \mathrm{C}$. This temperature generated a weak background defect of $\mathrm{DD} / \mathrm{VD}$ projection in wild-type animals, but no augmentation was observed in the single weak-allele mutants. In contrast, the double-weak mutants, mab-20(bx61);plx-2(ev775), mab-20(bx61);ptp-3(ok244), and plx-2(ev775) ptp-3(ok244) showed significant augmentation $\left(F_{(6,43)}=9.60, p<0.0001\right.$, ANOVA $)$ of the guidance defect in $\mathrm{DD} / \mathrm{VD}$ dorsal nerve cord (Fig. 1C). Thus, sema2a (mab-20), $p l x-2$, and $p t p-3$ genetically interact to regulate $\mathrm{DD} / \mathrm{VD}$ axonal projection in C. elegans.

We next examined the physical interaction of Plexin-2 and PTP-3. HA-tagged PTP-3 and Myc-tagged Plexin-2 were coexpressed in HEK293T cells and subjected to HA-immunoprecipitation. Coprecipitation of Myc-Plexin-2 with HA-PTP-3 confirmed the direct interaction of the two proteins (Fig. 1D). As Plexin-2 is a Sema2A receptor, the effect of PTP-3 on Sema2A-Plexin-2 interaction was tested. Sema2A-Fc-AP, a probe of Sema2A fused with human IgG Fc 

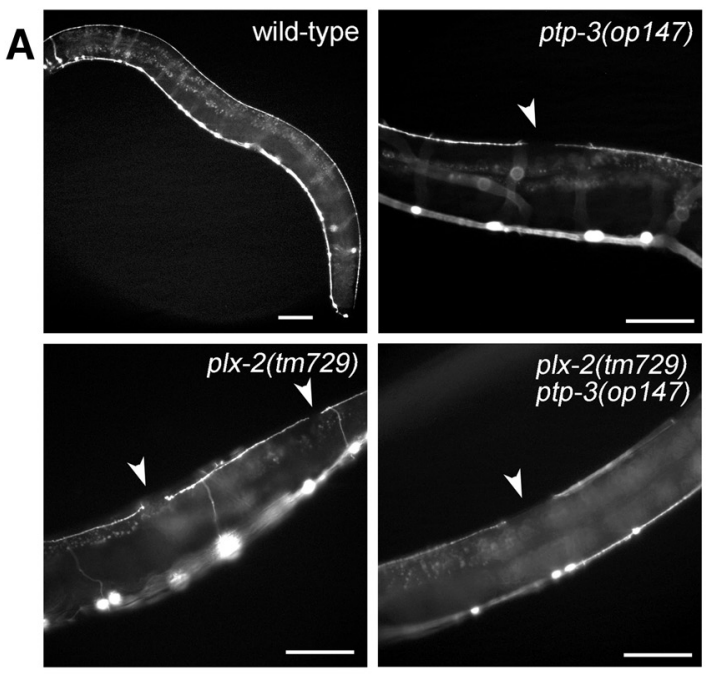

D

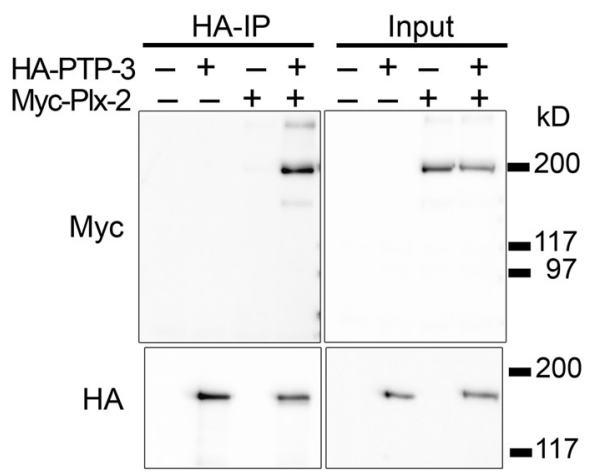

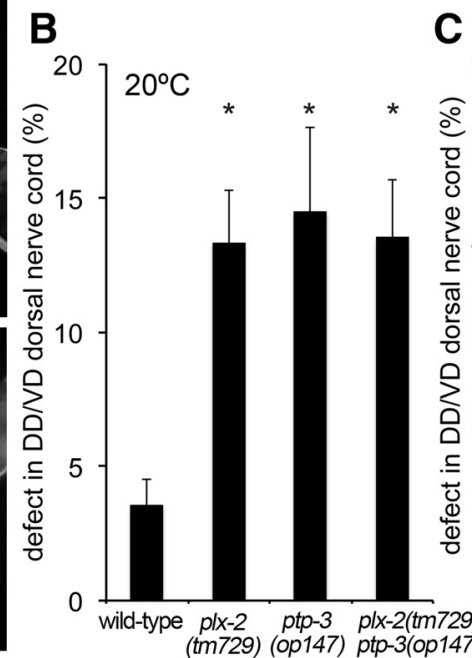
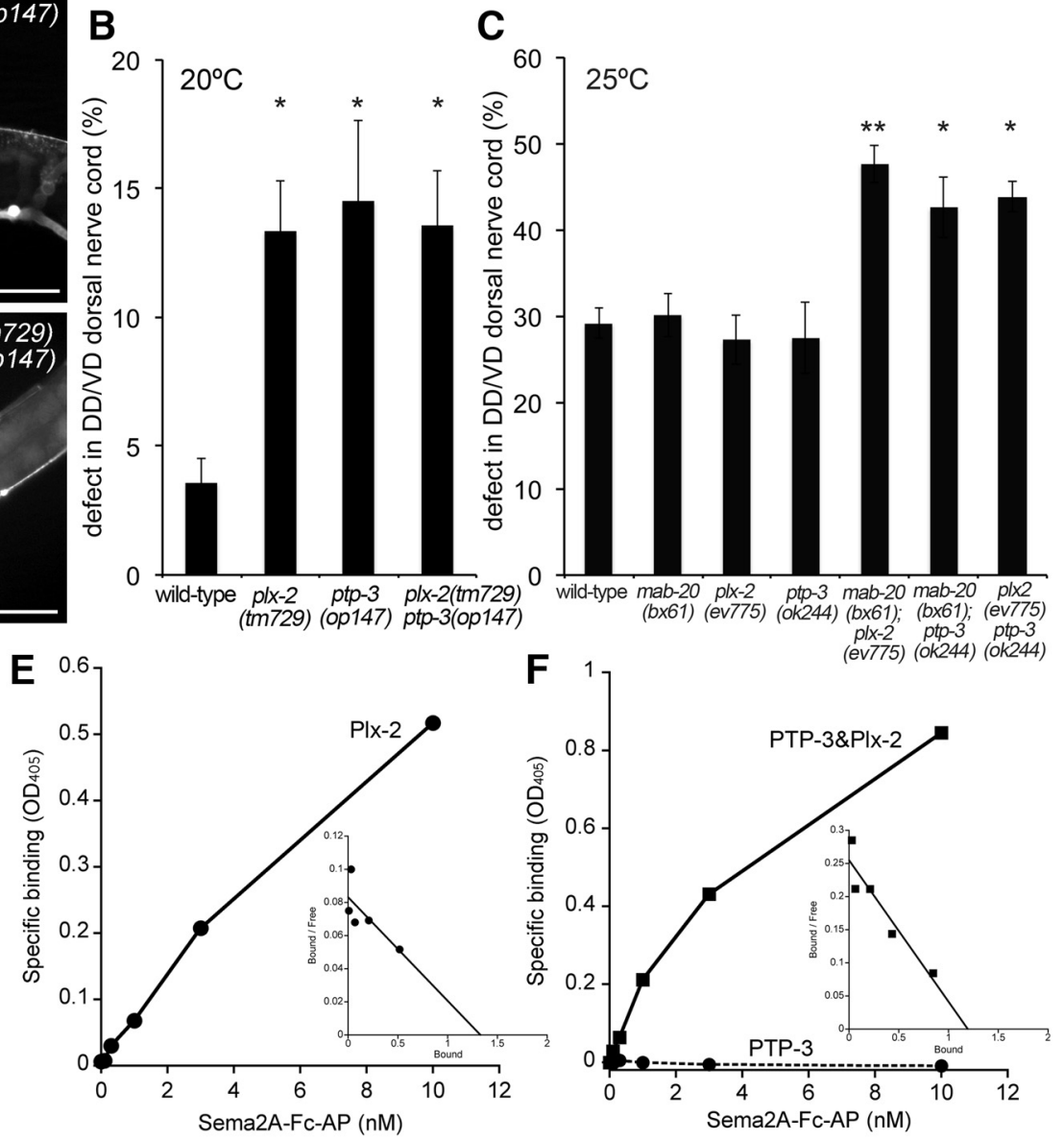

Figure 1. Involvement of PTP-3 in Sema2A-Plexin-2 signaling in C. elegans. A, Dorsal nerve cord of DD/VD neurons in wild-type (wt), plx-2(tm729), ptp-3(op147), and plx-2(tm729) ptp3(op 147). DD/VD neurons were visualized by oxls12 [unc-47::gfp]. In wild-type, DD/VD neurons form a single and continuous dorsal nerve cord. Both single mutants, plx-2(tm729) and ptp3(op147), exhibit a "gapped" dorsal nerve cord (arrowheads), which represents premature termination of DD/VD neurons. The double-mutant of plx-2(tm729) ptp-3(op 147) also shows a similar phenotype. Scale bars, $50 \mu \mathrm{m}$. B, Scored graph of the irregularity of DD/VD dorsal nerve cord. Single strong-allele mutants of $p / x-2(t m 729)$ and $p t p-3($ op 147$)$, and the double-mutant $p / x-2(t m 729)$ ptp-3(op147) show similar penetrance of the gap defect. Each bar represents average \pm SEM (wild-type, 8; plx-2(tm729), 7; ptp-3(op 147), 10; plx-2(tm729) ptp-3(op147), 7 assays). 0ne-way ANOVA with post hoc Tukey-Kramer test compared with wild-type. ${ }^{*} p<0.05$. C, Genetic interaction of the weak-allele mutants. Wild-type animals, single weak-allele mutants, mab-20(bx61), $p / x-2\left(\right.$ ev 775), $p t p-3(o k 244)$, and their double mutants were cultured at $25^{\circ} \mathrm{C}$. These double mutants show increased penetrance of the gap defect. Each bar represents average \pm SEM $(7$ assays, except mab-20(bx61);ptp-3(ok244),8 assays). One-way ANOVA with post hoc Tukey-Kramer test compared with wild-type and the single mutants. ${ }^{*} p<0.05,{ }^{* *} p<0.01$.D, Interaction of Plexin-2 and PTP-3 proteins. HA-PTP-3 and Myc-Plexin-2 (Plx-2) were coexpressed in HEK293T cells. Myc-Plexin-2 is coimmunoprecipitated with HA-PTP-3. E, F, AP-fused Sema2A binding assay was done with HEK293T cells expressing Plexin-2 with or without PTP-3. Sema2A-Fc-AP binding to Plexin-2 with or without PTP-3. In this experiment, the AP probe binds to Plexin-2 with a Kd of $16.0 \mathrm{~nm}$ (E). Coexpression of PTP-3 augments the Sema2A-Fc-AP binding to Plexin-2 with a Kd of $4.68 \mathrm{~nm}(\boldsymbol{F}$, solid line), whereas the probe does not bind to PTP-3 (F, dotted line).

region and human placental alkaline phosphatase, bound to Plexin-2 with a Kd of $12.5 \pm 1.66 \mathrm{nM}$ (Fig. 1E). Coexpression of PTP-3 augmented Sema2A-Fc-AP binding to Plexin-2 to yield a Kd of $4.53 \pm 0.65 \mathrm{~nm}$ (Fig. $1 F$, solid line). In contrast, no direct binding to PTP-3 was observed (Fig. $1 F$, dotted line). Thus, PTP-3 may act as a coreceptor of Plexin-2 in Sema2A signaling in C. elegans.

\section{PTP $\delta$ participates in Sema3A-induced growth cone collapse} in mouse neurons

As Sema3A is prototypic vertebrate Semaphorin, which exhibits repulsion for wide-range neurons, the involvement of LAR class PTPs in Sema3A-signaling was investigated. In situ hybridization analysis revealed that the mRNAs for $L A R, P T P \delta$ and PTP $\sigma$ were expressed in Sema3A-sensitive neurons, including DRG, cortical plate, and hippocampal formation in late (E16-E17) embryonic stages (Fig. 2A). PTP $\delta$ expression in hippocampal CA1 region was limited compared with the expression in cortical plate. This trend is consistent with previous reports (Schaapveld et al., 1998; Shishikura et al., 2016). Functional involvement of these PTPs in
Sema3A-signaling was examined next, by gene silencing with small interfering RNA (siRNA; Fig. 2B). The siRNAs against $L A R$, $P T P \delta$, or $P T P \sigma$ suppressed the targeted-PTP expression in COS-7 cells, however, weak off-target effects within the LAR family were also observed (Fig. 2Ba). Mouse E16 DRG explants were transfected with one of these siRNAs and the knockdown of protein expression was confirmed by immunocytochemistry (Fig. $2 B b-B d)$. Suppression of the protein expression was similar between the targets (Fig. 2Be). Although none of the siRNA transfection affected the growth cone morphology, Sema3A-induced growth cone collapse response was attenuated in neurons transfected with $P T P \delta$ siRNA, and not with $L A R$ or $P T P \sigma$ siRNA (Fig. $2 C, D)$. The difference of PTP $\delta$ RNAi and other conditions was statistically significant $\left(F_{(3,36)}=20.1, p<0.0001\right.$, ANOVA $)$. Physical interaction of PTP $\delta$ and Sema3A-receptor components was assessed by immunoprecipitation. Transiently expressed PTP $\delta$-Myc was coimmunoprecipitated with HA-NRP1 or HAPlexin-A1 from HEK293T cells (Fig. 2E). LAR-Myc and PTPoMyc also associated with HA-NRP1 or HA-Plexin-A1 in the same 
A Spinal Cord

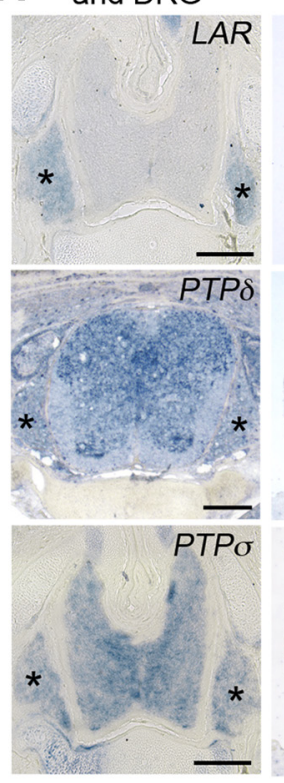

Cortex and Hippocampus
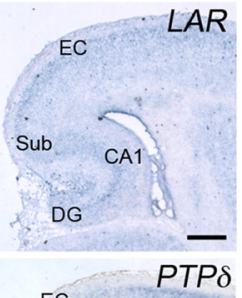

EC
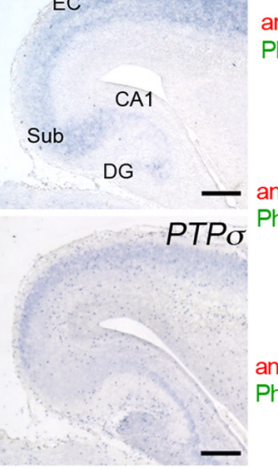

a

LAR-myc

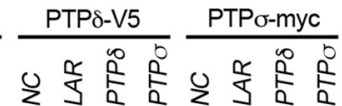
Myc, V5 - - - - - -

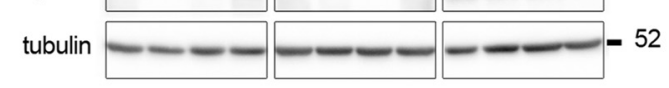

\section{b}

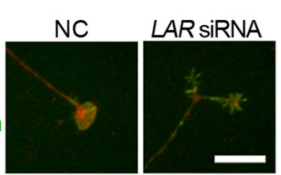

\section{e
${ }^{120}$}

$\square \mathrm{NC}$ - PTP SIRNA

C

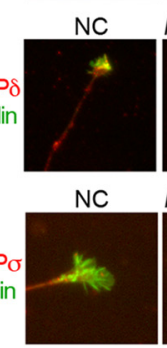

PTPS SiRNA
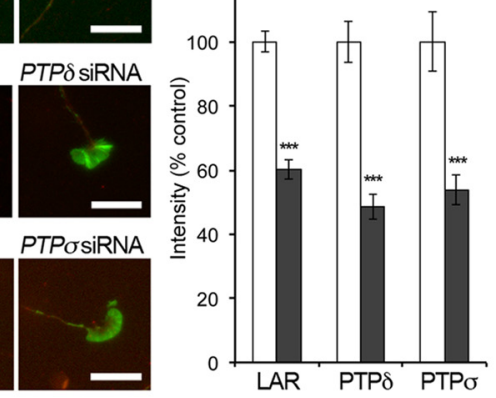

C

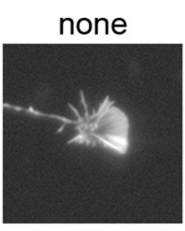

Sema3A

SiRNA

NC
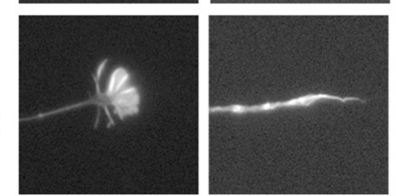

PTPS
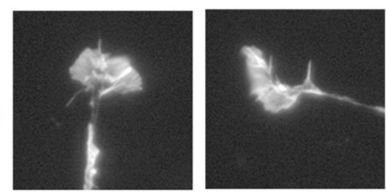

PTPo
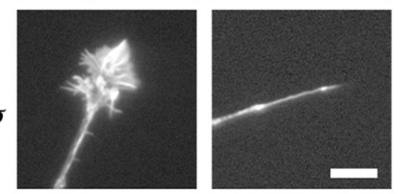
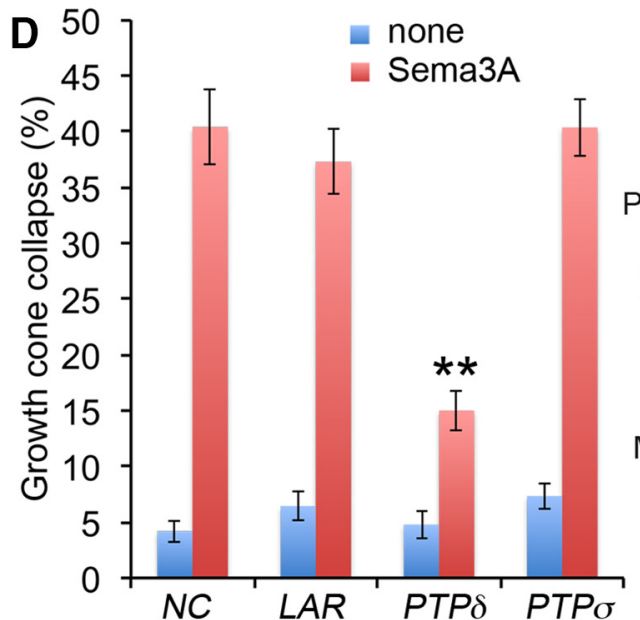

$\mathbf{E}$

Myc-IP

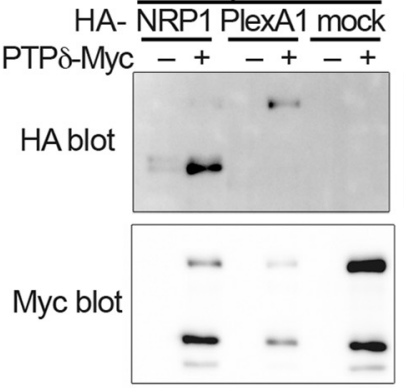

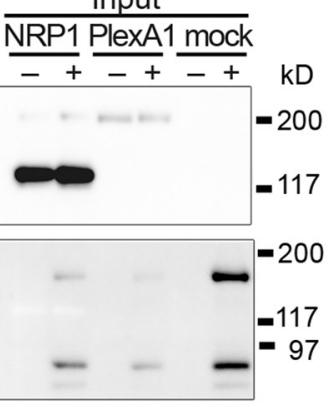
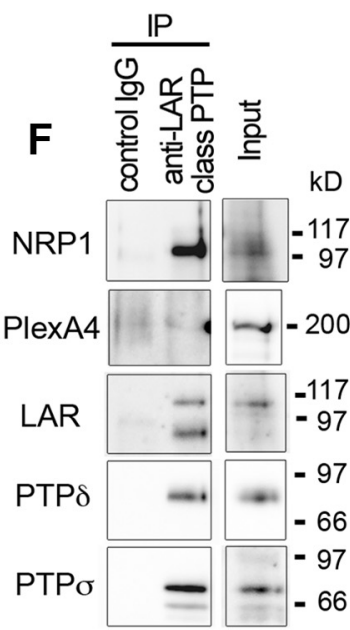

Figure 2. Involvement of PTP $\delta$ in Sema3A-induced growth cone collapse response. $A$, In situ hybridization for $L A R, P T P \delta$, and $P T P \sigma$ mRNAs in mouse $E 17$ nervous system. $L A R, P T P \delta$, and $P T P \sigma$ are expressed in DRG and spinal cord. These mRNAs are also expressed in cortical plates and hippocampal formation. Scale bars, $100 \mu m$. CP, Cortical plate; EC, entorhinal cortex; Sub, subiculum; CA1, CA1 region of hippocampal plate; DG, dentate gyrus. Ba, Suppression of transiently expressed Myc- or V5-tagged LAR, PTP $\delta$, and PTP $\sigma$ in COS-7 cells with cotransfection of their specific siRNAs. Immunoblotting with anti-myc or anti-V5 antibodies revealed that the siRNAs against $L A R, P T P \delta$, or PTP $\sigma$ suppressed targeted proteins. Weak off-target effects of these siRNAs within the LAR family were also noticed. Anti-tubulin immunoblots were done as loading controls. $\boldsymbol{B} \boldsymbol{b}-\boldsymbol{B} \boldsymbol{d}$, Reduction of immunoreactive signal in siRNA transfected neurons. Mouse DRG neurons were transfected with the control siRNA, LAR, PTP $\delta$, or PTP $\sigma$ siRNAs. The cells were immunostained with the indicated specific antibodies (red) and AlexaFluor 488 -Phalloidin (green). Scale bars, $10 \mu m$. Be, Quantified graph. Bar graph indicates the intensity of PTP-immunoreactive signals in growth cones. In each condition, $30-50$ growth cones were analyzed. The intensity in control siRNA-transfected neurons was treated as $100 \%$. The immunoreactive signal of each member decreased by $50-60 \%$ in specific siRNA transfected cells. Unpaired $t$ test between control and target siRNA (LAR: $t_{(65)}=9.05$, $p<0.0001 ;$ PTP $\delta: t_{(88)}=6.76, p<0.0001 ;$ PTP $\left.\sigma: t_{(80)}=4.36, p<0.0001\right) .{ }^{* * *} p<0.001$. C, RNAi knockdown of LAR class PTPs in DRG neurons. E17 mouse DRG neurons were transfected with

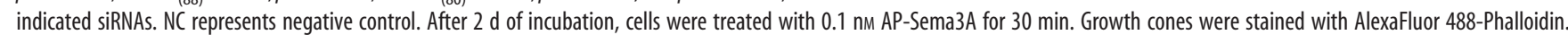
Introduction of PTPS siRNA but not LAR or PTP $\sigma$ siRNA suppresses Sema3A-induced growth cone collapse. Scale bar, $10 \mu \mathrm{m}$. D, Quantified graph. Each bar represents the average \pm SEM (NC, 11 ; $L A R, 8 ; P T P \delta, 10 ; P T P \sigma, 11$ explants from more than four independent cultures), one-way ANOVA with post hoc Tukey-Kramer test compared with other conditions treated with AP-Sema3A. ${ }^{* *} p<0.01$. E, Coimmunoprecipitation of HA-NRP1 and HA-Plexin-A1 (PlexA1) with PTP $\delta$-Myc from HEK293T cells. The cells were transfected with the indicated expression vectors and subjected to anti-Myc immunoprecipitation. HA-NRP1 and HA-Plexin-A1 were coprecipitated with PTP $\delta$-Myc. $\boldsymbol{F}$, Coimmunoprecipitation of NRP1 with LAR class PTPs from mouse brain. NRP1, but not Plexin-A4 (PlexA4), was coimmunoprecipitated with LAR class PTPs from the solubilized mouse E16 brain membrane fractions.

system (data not shown). Endogenous LAR class PTPs in P0 mouse brains were immunoprecipitated with NRP1 from detergent-solubilized membrane fractions (Fig. $2 F$ ). As coprecipitation of Plexin-A4 from the brain was not clearly observed (Fig. $2 F$ ), the interaction of LAR class PTPs and Plexin-A may be dynamic and/or transient in vivo.

We next evaluated Sema3A-induced collapse activity for $\operatorname{Ptp} \delta^{-I-}$ DRG neurons. As expected, the response was attenuated in E17 DRG neurons from $\mathrm{Ptp} \delta^{-/-}$compared with the neurons from wild-type (Fig. 3A). To determine whether the catalytic activity of PTP $\delta$ is required for Sema3A-signaling, we examined a rescue study. Cultured DRG explants from E16-E17 Ptp $\delta^{+/-}$or $P t p \delta^{-1-}$ were infected with recombinant herpes simplex virus harboring V5-tagged PTP $\delta$ wild-type or phosphatase-inactive D1(C/S) mutant. DRG neurons from $P t p \delta^{-1-}$ infected with mock vector were less sensitive to Sema3A-stimulation compared 
A

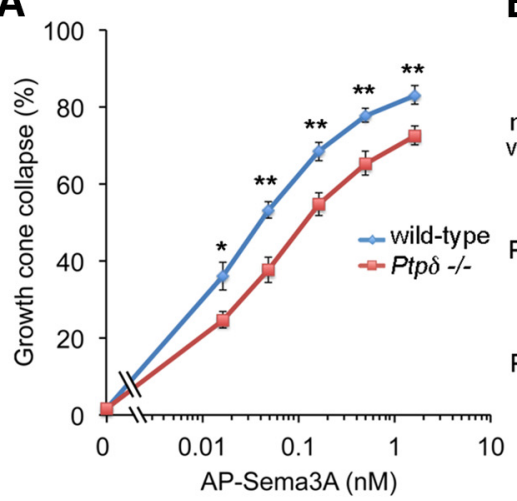

B

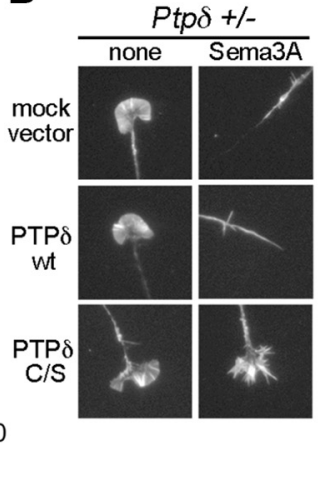

C

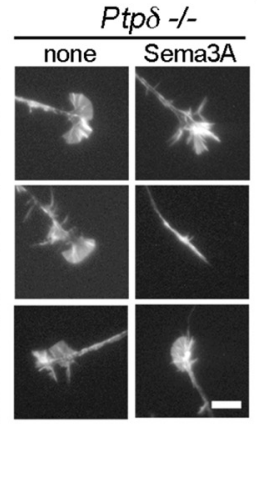

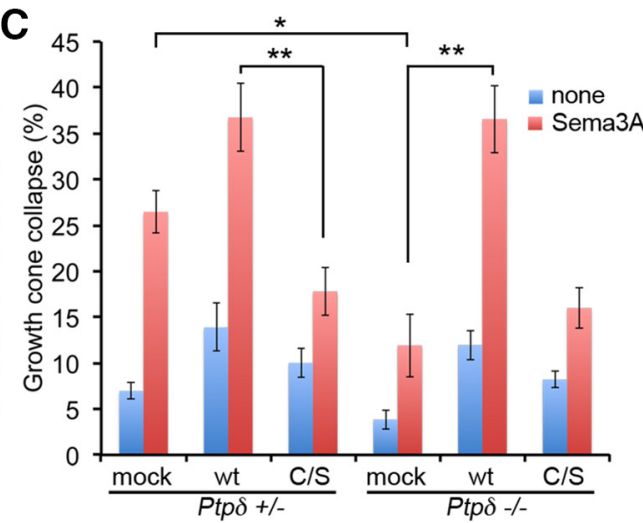

Figure 3. Involvement of enzymatic activity of PTP $\delta$ in Sema3A-signaling. $A$, Dose-response of Sema3A-induced growth cone collapse of embryonic DRG neurons from E17 wild-type and $P \operatorname{tp} \delta^{-1-}$ mice. The sensitivity was attenuated in the knock-out DRG neurons compared with wild-type neurons. Each point represents the average \pm SEM ( $n=12$ ). Unpaired $t$ test between wild-type and Ptp $\delta^{-1-}\left(0 \mathrm{~nm}: t_{(22)}=0.07, p=0.94 ; 0.016 \mathrm{~nm}: t_{(22)}=2.68, p=0.014 ; 0.049 \mathrm{~nm}: t_{(22)}=3.78, p=0.001 ; 0.16 \mathrm{~nm}: t_{(22)}=3.58, p=0.0017 ; 0.49 \mathrm{~nm}: t_{(22)}=3.36, p=0.0028\right.$; 1.64 nм: $\left.t_{(23)}=3.12, p=0.0048\right) .{ }^{*} p<0.05,{ }^{* *} p<0.01$. B, Rescue experiments with HSV-PTP $\delta$ wt and D1(C/S) phosphatase-inactive mutant (C/S). Primary cultured DRG neurons from E16 $P \operatorname{tp} \delta^{+/-}$and $\operatorname{Ptp} \delta^{-/-}$embryos were infected with recombinant HSV harboring PTP $\delta$ wild-type or D1(C/S) mutant. Sema3A-induced collapse response was examined. Overexpression of PTP $\delta$-wild-type but not D1(C/S) mutant in Ptp $\delta^{-1-}$ neurons rescues Sema3A-sensitivity. Scale bar, $10 \mu \mathrm{m}$. C, Scored graph. mock, Mock vector; C/S, D1(C/S) mutant. Each bar represents the average $\pm \operatorname{SEM}\left(n=10-11\right.$, each condition from 5 independent cultures). Blue bars, no stimulation; red bars, 0.03 nm AP-Sema3A stimulation. 0 ne-way ANOVA $\left(F_{(5,57)}=12.27, p<0.0001\right)$ with post hoc Tukey-Kramer test. ${ }^{*} p<0.05,{ }^{* *} p<0.01$.

Table 2. Penetrance of ectopic projection of entorhinal axons in stratum radiatum

\begin{tabular}{|c|c|c|c|c|c|c|}
\hline & Wild-type & $P t p \delta^{+/-}$ & $\operatorname{Ptp} \delta-/-$ & Sema3a $a^{+/-}$ & Sema3a-1- & $\begin{array}{l}\operatorname{Ptp} \delta^{+/-} ; \\
\text {Sema3a }\end{array}$ \\
\hline Irregular & 4 & 5 & 7 & 7 & 5 & 6 \\
\hline Normal & 12 & 5 & 2 & 7 & 0 & 3 \\
\hline Irregularity, \% & 25 & 50 & 77.8 & 50 & 100 & 66.7 \\
\hline Fisher's exact test (vs wild-type) $p$ value & - & 0.234 & $0.0168^{*}$ & 0.257 & $0.00619^{* *}$ & 0.0872 \\
\hline
\end{tabular}

${ }^{*} p<0.05,{ }^{* *} p<0.01$.

with the neurons from $P t p \delta^{+/-}$with the same infection (Fig. $3 B, C$ ). Re-expression of PTP $\delta$ wild-type but not of PTP $\delta$-D1 $(\mathrm{C} / \mathrm{S})$ in $P t p \delta^{-1-}$ neurons rescued Sema3A-sensitivity (Fig. $3 B, C$ ). Although statistically insignificant, $\mathrm{PTP} \delta$-D $1(\mathrm{C} / \mathrm{S})$ tended to inhibit Sema3A-collapse response in heterozygous neurons in a dominant-negative manner (Fig. 3B,C). These results suggest that PTP $\delta$ mediates Sema 3 A signaling via its phosphatase activity.

\section{PTP $\delta$ participates in entorhinal-}

\section{hippocampal projection, but not in a} Sema3A-dependent manner

We analyzed several axonal projections in $P t p \delta^{-I-}$ mice along with wild-type or heterozygous littermates to explore the involvement of PTP $\delta$ in Sema3A-mediated in vivo axon guidance. The peripheral projection of sensory fibers in E13Ptp $\delta^{-1-}$ embryos was almost identical to wild-type (data not shown, available on request). Previous studies showed the predominant expression of PTP $\delta$ in the CNS (Sommer et al., 1997; Shishikura et al., 2016). Before analyzing the axonal projection in CNS, we examined in vitro collagen-gel repulsion assay of several Sema3A-sensitive forebrain regions including entorhinal cortex and hippocampal CA1 (Chédotal et al., 1998; Steup et al., 1999; Pozas et al., 2001). We found that the axons from knock-out entorhinal explants were less sensitive to Sema3A in the repulsion assay as well as in growth cone collapse assay (data not shown, available on request). bars, $50 \mu \mathrm{m}$.
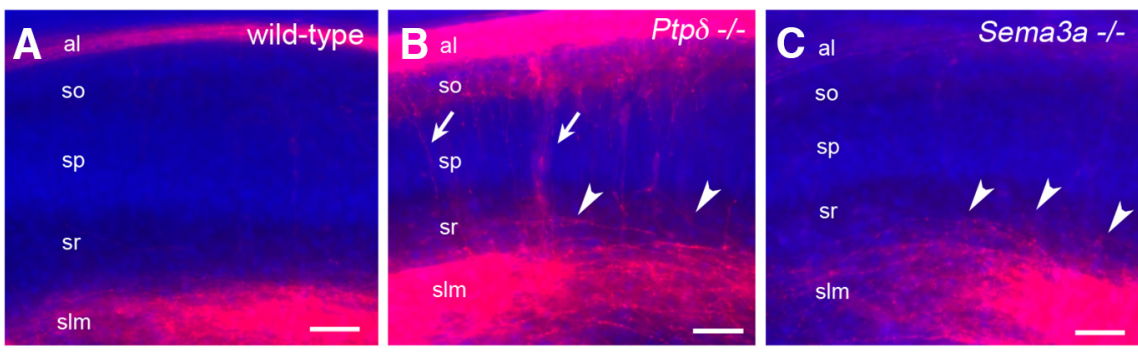

Figure 4. Entorhino-hippocampal projection in Ptp $\delta$ and Sema3a mutants. $\boldsymbol{A}$, Wild-type. The projection was restricted in the stratum lacunosum-moleculare (slm). $\boldsymbol{B}, P t p \delta^{-1-}$. The ectopic axons innervated the stratum oriens (so) and pyramidal cell layer (sp) from hippocampal white matter (al, arrows). Irregular projection of single axons from sim to stratum radiatum (sr) is also noticed (arrowheads). C, Sema3a ${ }^{-1-}$. The irregular projection of single axons from slm to stratum radiatum (sr) is present in Sema3 $a^{-1-}$ brains (arrowheads); however, the ectopic projection from white matter ( $\boldsymbol{B}$, arrows) is absent. al, Hippocampal alveus (white matter); so, stratum oriens; sp, stratum pyramidale; sr, stratum radiatum; slm, stratum lacunosum-moleculare. Scale

We then examined the entorhino-hippocampal projection by DiI-tracing. In wild-type brains, the entorhinal axonal projection was restricted to the stratum lacunosum-moleculare and hippocampal alveus in CA1 region (Fig. $4 A$ ). In contrast, $P t p \delta^{-l-}$ entorhinal axons irregularly invaded into the stratum radiatum from the stratum lacunosum-moleculare (Fig. $4 B$, arrowheads). The hippocampal alveus of $\operatorname{Ptp} \delta^{-/-}$was strongly labeled with DiI (Fig. $4 B$, al). Furthermore, many fibers in the alveus turned into the stratum radiatum through the pyramidal cell layer (Fig. $4 B$, arrows). We measured the width of DiI-labeled alveus and found that the width in $P t p \delta^{-/-}(122.2 \pm 6.5 \%, n=9)$ was significantly larger than in wild-type $\left(100.0 \pm 7.1 \%, n=9 ; t_{(16)}=2.30, p=\right.$ 0.035 , unpaired $t$ test). We termed this phenotype "over- 

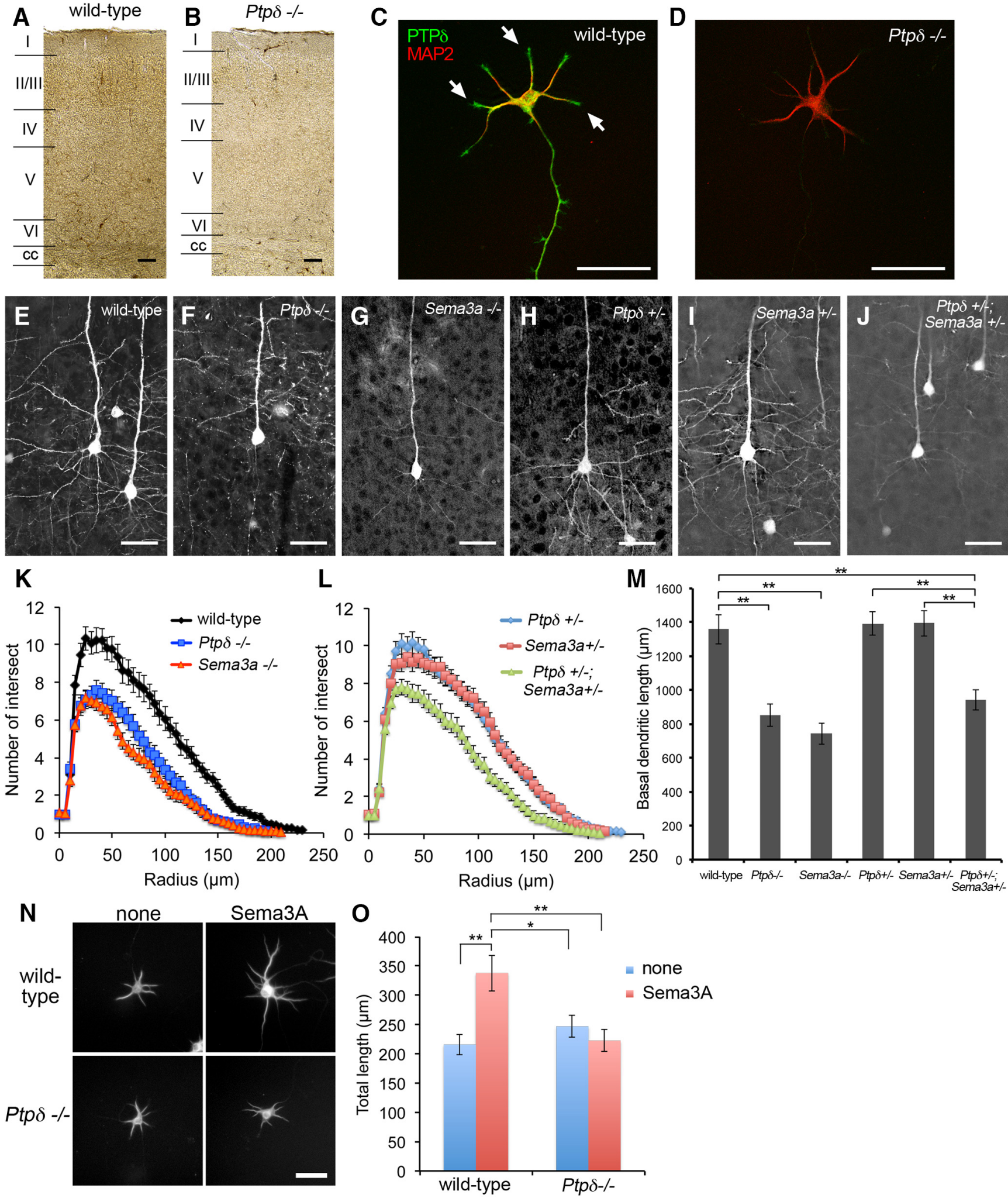

Figure 5. Dendritic arborization of cortical layer V pyramidal neurons in Ptp $\delta$ mutant mice. $A, B$, Immunohistochemistry of PTP $\delta$ in cerebral cortex. Coronal sections (motor area) from wt and $P t p \delta^{-1-}$ brains ( 3 weeks) were immunostained with anti-PTP $\delta$ mAb. PTP $\delta$ is predominantly expressed in cortical layers II/III and V in wt (A). Corpus callosum (cc) also shows strong signal (A). These signals are reduced in Ptp $\delta^{-1-}$ specimens $(\boldsymbol{B})$. Scale bars, $100 \mu \mathrm{m}$. C, D, Immunocytochemistry of PTP $\delta$ and MAP2 in primary cultured cortical neurons. Dissociated cortical neurons from wild-type and Ptp $\delta^{-1-}$ embryos (E14) were cultured on PLL-coated glass coverslips for $8 \mathrm{~d}$. PTP $\delta$ and MAP2 expressed in the neurons were visualized with green and red signals, respectively. PTP $\delta$ is colocalized with MAP2 in the dendritic neurites of wild-type neurons (C).PTP $\delta$ is also present in dendritic growth cones (C, arrows). These signals are absent in Ptp $\delta^{-1-}$ neurons (D). Scale bars, $50 \mu \mathrm{m} . \boldsymbol{E}-\boldsymbol{J}$, Dendritic arborization of cortical layer V pyramidal neurons. The pyramidal neurons were visualized by intercrossing GFP-M with wt, Sema3a, and Ptp $\delta$ mutant mice. Wild-type, $6-9$ thick, and long basal dendrites are arborized from the pyramidal neurons $(\boldsymbol{E})$. Ptp $\delta^{-1-}$ and Sema3a ${ }^{-1-}$ display thin and short arborization of basal dendrites $(\boldsymbol{F}, \boldsymbol{G})$. Ptp $\delta^{+/-}$and $\operatorname{Sema3a^{+/-}}$ single-heterozygotes show normal development of basal dendrites $(\boldsymbol{H}, I) \cdot P \operatorname{tp} \delta^{+/-} ;$Sema3a ${ }^{+/-}$double-heterozygous mutants exhibit retarded growth of cortical basal dendrites $(J)$. Scale bars, $50 \mu \mathrm{m} . K, \mathbf{L}$, Sholl analysis. Average \pm SEM of 24-31 different pyramidal neurons from three independent animals are shown. The complexity of cortical (Figure legend continues.) 
projection". Sema3a $a^{-1-}$ brains also showed ectopic entorhinal fibers in the stratum radiatum (Fig. 4C, arrowheads; Pozas et al., 2001), but over-projection was absent.

Because the ectopic projection of entorhinal axons into stratum radiatum is a shared phenotype in $P t p \delta^{-1-}$ and Sema3a $a^{-1-}$, we examined the penetrance of this phenotype in both homozygotes as well as in single- and double-heterozygote mutants. As shown in Table 2, the penetration was significantly increased in both homozygous mutants compared with that in wild-type. In addition, $P t p \delta^{+/-}$, Sema $3 a^{+/-}$and $P t p \delta^{+/-} ; S_{e m a 3 a^{+/-}}$also exhibited the irregular projection; however, those penetrations were statistically insignificant compared with wild-type. Thus, in vivo, the contribution of PTP $\delta$ in Sema3A-regulated entorhinohippocampal projection is thought to be limited. Other Sema3Asignaling components, such as Plexin-A4 and/or L1, may play a critical role in this axon guidance.

\section{PTP $\delta$ is involved in Sema3A-regulated dendritic growth of cortical pyramidal neurons}

The protein expression of PTP $\delta$ in mouse brain was increased in the postnatal telencephalon, including cortical plate and hippocampal formation (Shishikura et al., 2016). In rodents, dendritic arborization and synaptic generation of cortical and hippocampal neurons proceed during the first month of postnatal stage (Meller et al., 1968; Minkwitz and Holz, 1975). It has been shown that both Plexin-A4 $4^{-1-}$ and Npn-1 $1^{\text {sema- }}$ mice exhibit poor elaboration of the basal dendrites of cortical layer $\mathrm{V}$ pyramidal neurons (Gu et al., 2003; Tran et al., 2009). Immunohistochemistry revealed that mouse neocortex predominantly expressed PTP $\delta$ in layers II/III and V as well as in corpus callosum (Fig. $5 A, B$ ). In addition, $\mathrm{PTP} \delta$ was localized in the dendritic neurites and their growth cones of primary cultured cortical neurons from E14 wild-type embryos, but not from $P t p \delta^{-1-}$ (Fig. $5 C, D)$. We thus examined the cortical dendritic arborization of $P t p \delta$ mutant mice. To visualize layer $\mathrm{V}$ cortical pyramidal neurons in vivo, Ptp $\delta$ mutant mice were crossbred with a thy $1-G F P-m$ transgenic mouse line, which expresses GFP in a small subset of pyramidal neurons (Feng et al., 2000). Wild-type showed that thick and long basal dendrites were arborized from the layer $\mathrm{V}$ pyramidal neurons (Fig. 5E). In contrast, thin and short dendrites were elaborated from $P t p \delta^{-1-}$ pyramidal neurons (Fig. $5 F$ ). As expected, Sema3a $a^{-1-}$ showed a similar phenotype to $P t p \delta^{-1-}$ (Fig. 5G). Sholl analysis and total length of basal dendrites revealed poor development of cortical layer $\mathrm{V}$ basal dendrites in $P t p \delta^{-I-}$ as well as in Sema3a $a^{-1-}$ compared with wild-type (Fig.

$\leftarrow$

(Figure legend continued.) layer $\mathrm{V}$ basal dendrites in $\operatorname{Ptp} \delta^{-1-}\left(\boldsymbol{K}\right.$, blue) and Sema3a ${ }^{-1-}(\boldsymbol{K}$, red) is decreased compared with wild-type $\left(\boldsymbol{K}\right.$, black). $\operatorname{Ptp} \delta^{+/-} ;$Sema3 $a^{+/-}(\boldsymbol{L}$, green) also shows a similar reduction. $\boldsymbol{M}$, Total length of basal dendrites of each genotype. Sema $3 a^{-1-}$ and $P \operatorname{tp} \delta^{-1-}$ exhibit shorter length of basal dendrites than wild-type or single heterozygotes. The total length of $P \operatorname{tp} \delta^{+/-}$; Sema3a $a^{+/-}$double-heterozygotes is also shorter than that of Sema3a ${ }^{+/-}$, Ptp $\delta^{+/-}$, or wt. One-way ANOVA $\left(F_{(5,167)}=17.05, p<0.0001\right)$ with post hoc Tukey-Kramer test (wt: 30; Ptp $\delta^{-/-}: 29 ;$ Sema3a ${ }^{-/-}: 24 ; \operatorname{Ptp}^{+/-}: 29 ;$ Sema3a $^{+/-}: 30$; $P \operatorname{tp} \delta^{+1-}$;Sema3a ${ }^{+/-}: 31$ neurons from 3 independent animals, each genotype). ${ }^{* *} p<0.01$. $N$, Dendritic outgrowth of primary cultured cortical neurons. Dissociated cortical neurons from wt and Ptp $\delta^{-1-}$ embryos (E17) were cultured for $6 \mathrm{~d}$ and then stimulated with Sema3A (0.3 nм) for $1 \mathrm{~d}$. The cells were immunostained with MAP2 to visualize dendritic branches. The dendritic growth of wt neurons but not of knock-outs is facilitated with Sema3A-stimulation. Scale bar, $50 \mu \mathrm{m} . \mathbf{0}$, Total dendritic length. Bar graphs indicate average \pm SEM. One typical example is shown. Other three independent cultures gave similar results. One-way ANOVA $\left(F_{(3,120)}=6.41, p=0.00046\right)$ with post hoc Tukey-Kramer test (wild-type none: 31 ; wild-type Sema3A: 28; $\operatorname{Ptp} \delta^{-1-}$ none: $35 ; \operatorname{Ptp} \delta^{-1-}$ Sema3A: 30 neurons). ${ }^{*} p<0.05,{ }^{* *} p<0.01$.
$5 K, M)$. Cortical pyramidal neurons from $P t p \delta^{+/-}$; Sema3a $a^{+/-}$ double-heterozygous mice also exhibited less elaborate basal dendrites compared with those of single heterozygotes (Fig. $5 \mathrm{H}-$ $J, L, M)$. In addition, Sema3A-stimulation of primary cultured cortical neurons induced the dendritic growth of wild-type neurons, but not of $P t p \delta^{-1-}$ neurons (Fig. $5 N, O$ ). These results indicate that $\mathrm{PTP} \delta$ genetically interacts with Sema3A to promote the dendritic arborization of cortical pyramidal neurons.

\section{PTP $\delta$ dephosphorylates and activates Fyn in Sema3A-signaling}

We hypothesized that PTP $\delta$ catalyzes tyrosine-dephosphorylation of specific protein substrates in the Sema3A-signaling cascades (Fig. $3 B, C)$. Loss of PTP $\delta$ in the knock-out mice would thereby result in hyperphosphorylation of such substrates in vivo. Immunoblotting analysis with anti-phosphotyrosine-specific antibody revealed that at least two proteins, of 100 and $60 \mathrm{kDa}$, were hyperphosphorylated in $P t p \delta^{-l-}$ brain homogenates (Fig. $6 A$ ). Because we previously reported the involvement of Fyn tyrosine kinase in Sema3A-signaling (Sasaki et al., 2002) and its molecular size is $\sim 60 \mathrm{kDa}$, we examined the phosphorylation of Fyn and the related Src kinases in Ptp $\delta$ mutant brains. As predicted, immunoprecipitated Src and Fyn from $P t p \delta^{-/-}$were hyperphosphorylated compared with those from either $P t p \delta^{+/-}$or wild-type mice brains (Fig. 6B). This finding is also consistent with the earlier observation (Chaudhary et al., 2015). It has been shown that the kinase activity of Src and Fyn is regulated by the phosphorylation of several tyrosine residues. Whereas phosphorylated Y416 (pY416) augments the kinase activity, phosphorylated C-terminal Y527 (pY527) binds to the intramolecular SH2domain of Src and Fyn to inhibit the kinase (Roskoski, 2005). Using specific antibodies, we found that the Y527 residue was predominantly phosphorylated in $P t p \delta^{-1-}$ brains (Fig. 6C). In cultured DRG neurons, the immunoreactive signal of pY527 was localized in the growth cones as well as in the axonal shafts (Fig. $6 D$, top left). Sema3A-stimulation induced the rapid dephosphorylation of pY527 in wild-type or $P t p \delta^{+/-}$growth cones (Fig. $6 D$, top right), whereas pY527 phosphorylation was unchanged in $P t p \delta^{-l-}$ growth cones (Fig. $6 D$, bottom right). The intensity of immunoreactive signals within the growth cones was analyzed (Fig. 6E) by setting the ratio of pY527 and Src (pY527/Src) in nonstimulated growth cones to be $100 \%$. The pY527/Src ratio in wild-type and $P t p \delta^{+/-}$(black solid line) was decreased after Sema3A-stimulation, whereas the ratio in $P t p \delta^{-1-}$ (red dashed line) was relatively unchanged. In addition, the growth cones from double-heterozygous embryos $P t p \delta^{+/-}$and $\mathrm{Fyn}^{+/-}$were less sensitive to Sema3A than from wild-type or singleheterozygous mutants $\left(F_{(3,30)}=5.89, p=0.0027\right.$, ANOVA; Fig. $6 F, G)$. Thus, PTP $\delta$ may dephosphorylate the pY527 residues upon Sema3A-stimulation to activate Src and Fyn in growth cones.

\section{Genetic interaction of Ptp $\delta$ and Fyn regulates the cortical dendritic growth}

We next examined the involvement of Src and Fyn-activation in Sema3A-mediated cortical dendritic growth. Primary cultured cortical neurons from E14 embryos were transiently stimulated with Sema3A and immunostained with pY527-Src, Src, and MAP2 antibodies. We found that the pY527-immunoreactive signal was localized in the dendritic processes and growth cones of wild-type neurons (Fig. 7A, top left, green signal). Sema3Astimulation reduced the pY527 signal in the dendrites (Fig. 7A, top right). As expected, this response was not observed in 

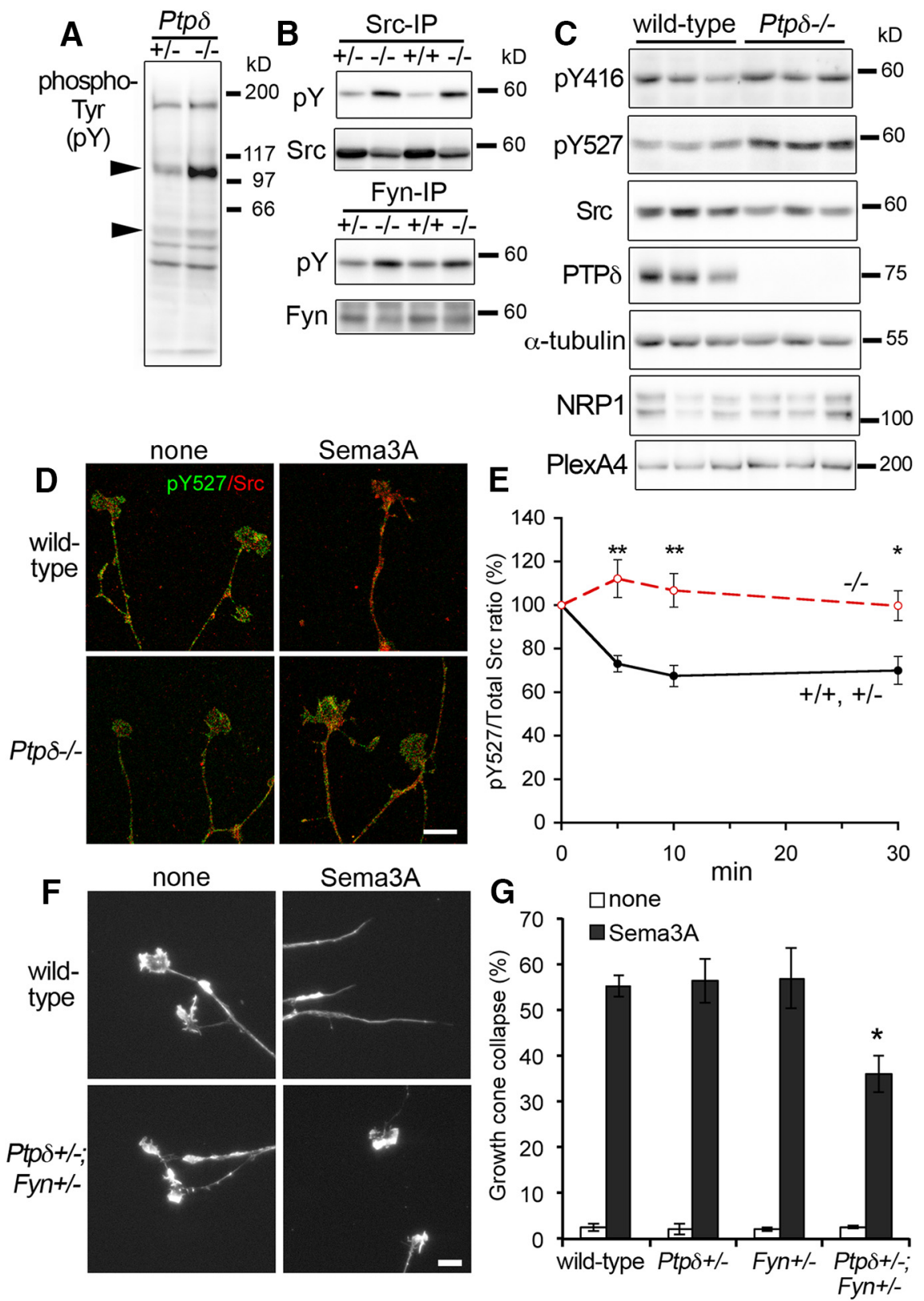

Figure 6. Dephosphorylation C-terminal Tyr 527 residues of Src and Fyn by PTP $\delta$. $\boldsymbol{A}$, Hyperphosphorylated proteins in Ptp $\delta$ mutant mice. Whole-brain lysates from $P t p \delta$ mutant mice were blotted with anti-phosphotyrosine mAb (4G10). Two immunoreactive bands, 100 and $60 \mathrm{kDa}$, are hyperphosphorylated in $P \operatorname{tp} \delta^{-\prime-}$ compared with $P \operatorname{tp} \delta^{+/-}$. B, Phosphorylation of Src and Fyn. Immunoprecipitated Src and Fyn from the indicated mutant mice were blotted with anti-phosphotyrosine mAb. Both Src and Fyn are hyperphosphorylated in $P \operatorname{tp} \delta^{-1-}$. C, Hyperphosphorylation of Y527-Src in Ptp $\delta^{-1-}$. Lysates from the indicated mutant mice were blotted with anti-phosphoY416-Src (pY416) or anti-phospho-Y527-Src (pY527)-specific antibodies. The phosphorylation of Y527 is increased in Ptp $\delta^{-1-}$ brains. D, Sema3A-induced dephosphorylation of pY527-Src in DRG growth cones. The neurons fromE16-E18 Ptp $\delta$ mutant mice were stimulated with AP-Sema3A (0.1 nm) and were double-immunostained with anti-pY527-specific pAb (green) and anti-Src mAb (red). Sema3Astimulation decreases pY527 in $P \operatorname{tp} \delta^{+\prime-}$ neurons, but not in $P \operatorname{tp} \delta^{-\prime-}$. Scale bar, $10 \mu \mathrm{m}$. E, Scored graph. The intensity of immunoreactive signals within the growth cones was analyzed. The ratio of pY527 and Src (pY527/Src) in nonstimulated growth cones was treated as $100 \%$. Each point represents the average $\pm \operatorname{SEM}\left(n=5\right.$, independent experiments). The pY527/Srcratio in wt and Ptp $\delta^{+/-}$(black solid line) is decreased after Sema3A-stimulation, whereas the ratio in $P \operatorname{tp} \delta^{-/-}$(red dashed line) is relatively unchanged. Unpaired $t$ test between $^{+1+}{ }^{+1-}$, and ${ }^{-1-}\left(5 \min : t_{(8)}=-3.57, p=0.0073 ; 10 \mathrm{~min}: t_{(8)}=-4.02, p=0.0038 ; 30 \mathrm{~min}: t_{(8)}=-3.16, p=\right.$ 0.013). ${ }^{*} p<0.05,{ }^{* *} p<0.01$. F, G, DRG neurons from $P \operatorname{tp} \delta^{+\prime-} ; F_{y n}{ }^{+\prime-}$ double-heterozygous are less sensitive to Sema3A stimulation. One-way ANOVA with post hoc Tukey-Kramer test (wt: 7;Ptp $\delta^{+/-}: 7 ; F_{y n}{ }^{+/-}: 7 ;$ Ptp $^{+/-} ;$Fyn $^{+/-}: 13$ explants from 3 independent experiments). ${ }^{*} p<0.05$. Scale bar, $10 \mu \mathrm{m}$.

$P t p \delta^{-1-}$ neurons (Fig. 7A, bottom). Quantification of pY527/Src ratio in the dendritic processes confirmed that Sema3A induced the dephosphorylation of pY527 in wild-type but not in $P t p \delta^{-1-}$ neurons (Fig. 7B).
Based on this Src/Fyn regulation, we examined the cortical dendritic arborization in $\mathrm{Fyn}^{-1-}$ and $\mathrm{Ptp} \delta^{+/-} ; \mathrm{Fyn}^{+/-}$ mutants. Compared with $\mathrm{Fyn}^{+/-}$or $P$ tp $\delta^{+/-}$ single-heterozygous brains, $\mathrm{Fyn}^{-/-}$and the double-heterozygous brains showed reduced arborization of the basal dendrites of cortical layer $\mathrm{V}$ pyramidal neurons (Fig. 7C-E). Quantitative analysis confirmed the reduction of the dendritic complexity and length in $\mathrm{Fyn}^{-1-}$ and in Ptp $\delta^{+/-} ; \mathrm{Fyn}^{+/-}$mutants (Fig. 7F,G). The phenotype in $F y n^{-1-}$ was identical to those in Sema3a $a^{-1-}$ and $P t p \delta^{-1-}$ (Fig. $5 F, G)$. The phenotypic augmentation in $P t p \delta^{+/-} ; F_{y n}{ }^{+/-}$further supports the in vivo interaction of PTP $\delta$ and Fyn (Fig. $7 E-$ $G)$. Together, Sema3A, PTP $\delta$, and Fyn act in the same signaling pathway to mediate the dendritic growth of cortical pyramidal neurons.

\section{Discussion}

Sema2A (mab-20) regulates epidermal enclosure of the embryo, morphogenesis of sensory rays of the male tail, and axon guidance of DA/DB and SDQL neurons (Roy et al., 2000; Chin-Sang et al., 2002; Wang et al., 2008). We previously reported that Sema2A and its receptor Plexin-2 (plx-2) are involved in the guidance and fasciculation of DD/VD neurons in the dorsal nerve cord (Nakamura et al., 2014). PTP-3, a LAR homolog PTP in $C$. elegans, is also involved in the epidermal enclosure, axon guidance of DA/DB and DD/VD neurons, and synapse formation (Chin-Sang et al., 2002; Harrington et al., 2002; Ackley et al., 2005). The similar defects in $m a b-20$, $p l x-2$, and $p t p-3$ mutants prompted us to test the genetic interaction of these genes. Because the ptp3(op147) strong-allele mutant did not augment the defect of DD/VD dorsalnerve cord in the plx-2(tm729)-null mutant (Fig. $1 A, B$ ), these genes may act in the same signaling pathway. This was further confirmed by the phenotypic augmentation in the weak allele double mutants, which combine any two of the following strains, mab-20(bx61), plx2(ev775), and ptp-3(ok244; Fig. 1C). Immunoprecipitation studies also demonstrated the physical interaction of PTP-3 and Plexin-2 (Fig. 1D). Coexpression of PTP-3 and Plexin-2 formed high affinity binding sites for Sema2A (Fig. $1 E, F)$. Because LAD-2, the L1 homolog in C. elegans, interacts with Plexin-2 and serves as a repulsive coreceptor for Sema2A in SDQL neurons (Wang et al., 2008), PTP-3 may form a Sema2A-functional receptor complex with Plexin-2 in DD/VD neurons. Interestingly, in ptp-3(op147) mutants, the catalytic 

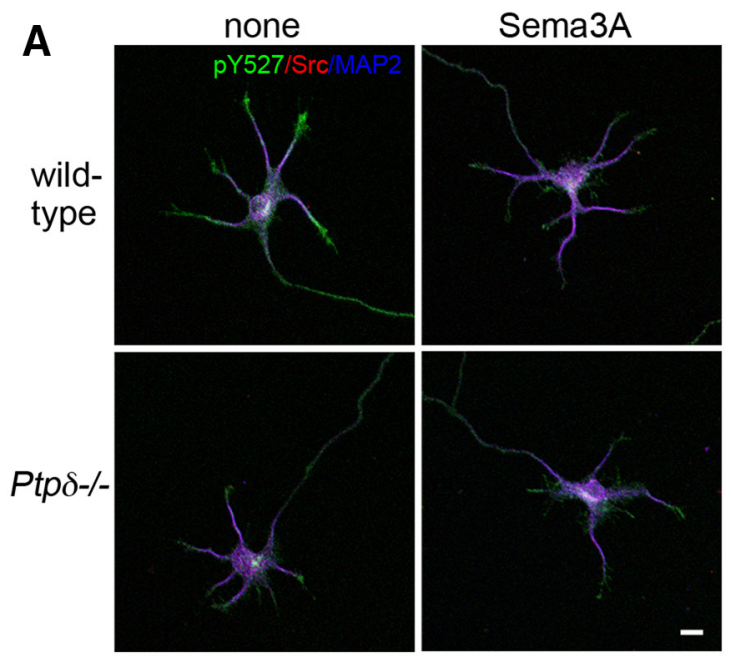

B
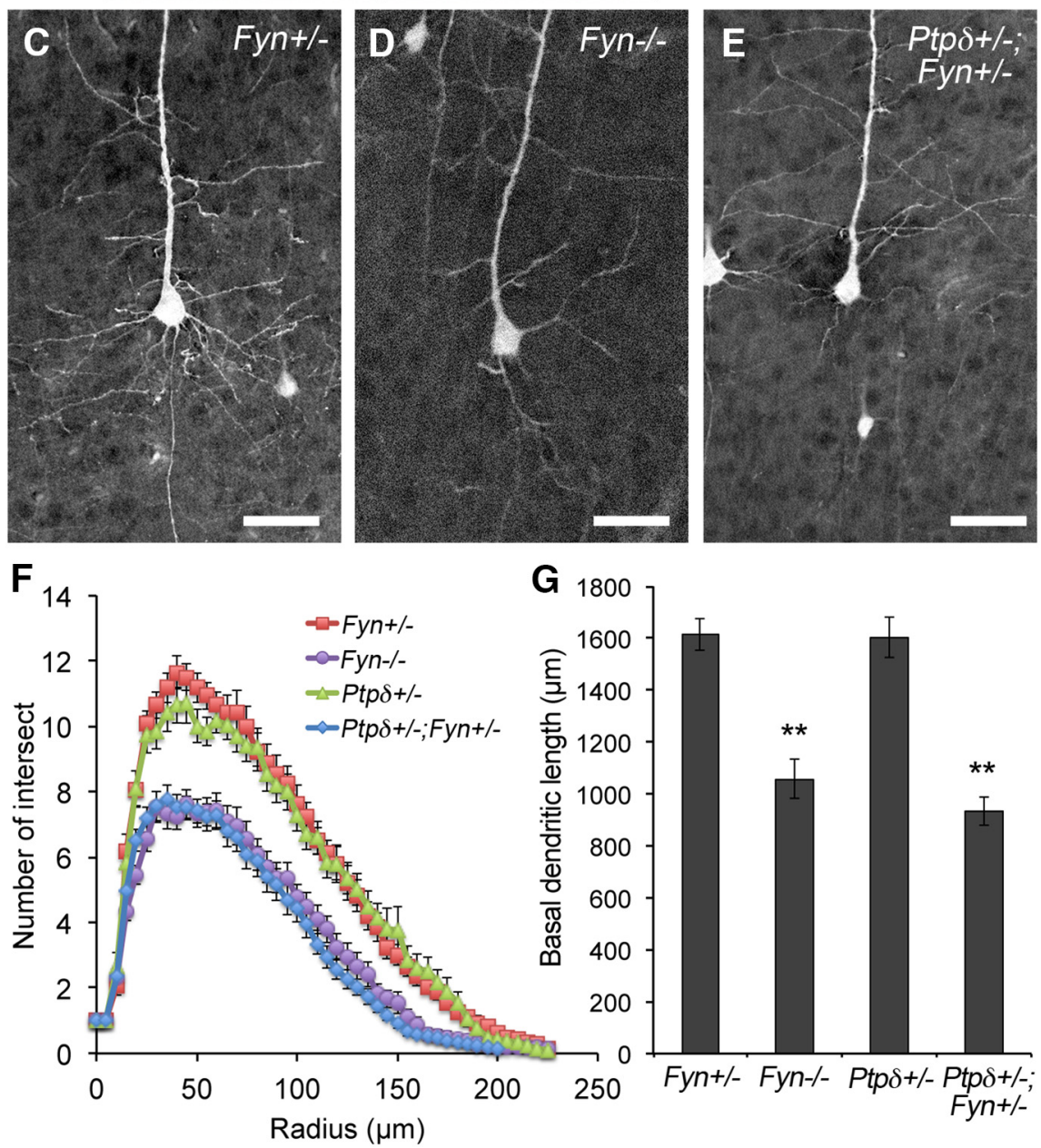

G 1800

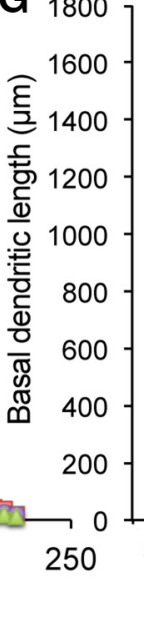

Fyn+/- Fyn-/- Ptpo+/- Ptp + +/-;

Figure 7. Genetic interaction of $P \operatorname{tp} \delta$ and Fyn in cortical dendritic growth. $A$, Sema3A-induced dephosphorylation of pY527-Src in cultured cortical dendrites. The cortical neurons from E14 wild-type and $P t p \delta^{-1-}$ embryos were cultured for $7 \mathrm{~d}$ and stimulated with AP-Sema3A ( $0.3 \mathrm{~nm})$ for $10 \mathrm{~min}$. The cells were immunostained with anti-pY527 (green), anti-Src (red), and anti-MAP2 (blue) antibodies. Sema3A-stimulation decreases pY527 in wild-type neurons, but not in $P$ tp $\delta^{-1-}$. Scale bar, $10 \mu \mathrm{m} . \boldsymbol{B}$, Scored graph. The intensity of immunoreactive signals in the dendritic processes was analyzed. The graph represents one typical result. The ratio of pY527 and Src (pY527/Src) in nonstimulated wt neurons was treated as 100\%. The pY527/Src ratio in wt is decreased after Sema3A-stimulation, whereas the ratio in $P t p \delta^{-1-}$ is relatively unchanged. Each bar represents the average \pm SEM. One-way $\operatorname{ANOVA}\left(F_{(3,46)}=4.15, p=0.011\right)$ with post hoc Tukey-Kramer test (wt none: 12; wild-type Sema3A: $12 ; \operatorname{Ptp} \delta^{-1-}$ none: 12; $P \operatorname{tp} \delta^{-1-}$ Sema3A: 14 neurons). ${ }^{*} p<0.05$. Four independent experiments gave similar results. $\boldsymbol{C}-\boldsymbol{E}$, Layer $V$ cortical neurons of Fyn $^{+1-}(\boldsymbol{C})$, Fyn $^{-1-}(\boldsymbol{D})$, and Ptp $\delta^{+/-} ;$Fyn $^{+/-}(\boldsymbol{E})$ visualized by GFP-M. Scale bars, $50 \mu \mathrm{m}$. $\boldsymbol{F}$, Sholl analysis. Average \pm SEM of $20-30$ different pyramidal neurons from two independent animals are shown. Fyn ${ }^{-1-}$ and $P \operatorname{tp} \delta^{+/-} ; F_{y n}{ }^{+/-}$exhibit less arborized basal dendrites than $\mathrm{Fyn}^{+/-}$or $P \operatorname{tp} \delta^{+/-}$, indicating genetic interaction of the two genes. $G$, Total length of basal dendrites. The length of $\mathrm{Fyn}^{-I-}$ and $\mathrm{Ptp} \delta^{-/-} ; \mathrm{Fyn}^{+/-}$are shorter than those of $\mathrm{Fyn}^{+/-}$or $\mathrm{Ptp} \delta^{+/-}$. One-way ANOVA
D1 phosphatase domain of PTP-3 is disrupted, but the extracellular and transmembrane regions are preserved (Harrington et al., 2002). Overexpression of PTP-3 short isoform in $p t p-3$ (op147) rescues the premature termination of DD/VD neurons (Ackley et al., 2005). Therefore, PTP-3 may mediate Sema2Asignaling by its catalytic activity.

We demonstrated the involvement of murine LAR class PTP in Semaphorinsignaling in vitro with primary cultured neurons. The knockdown of $P T P \delta$, one of the members of vertebrate LAR class PTPs, suppressed Sema3A-induced growth cone collapse response in mouse DRG neurons (Fig. 2C,D). DRG axons from E17 $P t p \delta^{-1-}$ embryos showed attenuated Sema3A-sensitivity compared with wildtype neurons (Fig. $3 A$ ). In addition, reexpression of PTP $\delta$ wild-type but not phosphatase-inactive mutant in $P t p \delta^{-/-}$ DRG neurons restored the sensitivity (Fig. $3 B, C)$. These data reveal a role for the enzymatic action of PTP $\delta$ in Sema3A-signaling.

However, PTP $\delta$ may not be an essential component for Sema3A-regulated in vivo axon guidance. Peripheral projections of sensory fibers were normal in $P t p \delta^{-1-}$ embryos (data not shown). Although the projection of entorhinal axons into hippocampal CA1 stratum lacunosum moleculare was disorganized in $P t p \delta^{-1-}$ as well as in Sema3a $a^{-1-}$ homozygous brains (Fig. 4A-C), these irregular projections were not observed in $P t p \delta^{+/-} ; \operatorname{Sema3a} a^{+/-}$ double-heterozygous brains (Table 2). In addition, the over-projection phenotype of $P t p \delta^{-1-}$ mice was absent in Sema3a ${ }^{-1-}$. These results suggest that in vivo contribution of PTP $\delta$ in Sema3A-regulated axon guidance is limited. Because over-projection is unique to $P t p \delta^{-1-}$ (Fig. $4 B$ ), PTP $\delta$ would be involved in the signaling of other guidance cues that restrict entorhinal axons into hippocampal alveus and suppress entering CA1 region.

In contrast to the minor contribution of PTP $\delta$ in Sema3A-regulated axon guidance, significant genetic interaction of Sema3a and $P t p \delta$ was observed in the arborization of cortical dendrites. Both Sema $3 a^{-1-}$ and $P t p \delta^{-1-}$ as well as $P t p \delta^{+/-} ;$Sema3 $a^{+/-}$double-heterozygous mice exhibited poor development of the basal dendrites of layer $\mathrm{V}$ cortical pyramidal neurons (Fig. 5). This is consistent with pre-

$\leftarrow$

$\left(F_{(3,99)}=29.52, p<0.0001\right)$ with post hoc Tukey-Kramer test (Fyn ${ }^{+/-}: 29 ; F_{y n}{ }^{-1-}: 24 ; P \operatorname{Ptp} \delta^{+/-}: 20 ; P \operatorname{tp} \delta^{+/-}$; Fyn ${ }^{+/-}: 30$ neurons). ${ }^{* *} p<0.01$. 
vious finding that primary cultured GFP-transfected Sema3 $a^{-1-}$ neurons showed poor dendritic development (Fenstermaker et al., 2004). The less elaborate dendritic growth of cortical pyramidal neurons has also been reported in Sema3A-receptor mutants such as $N p n-1^{\text {sema- }}$ mice, which express a mutant NRP1 abolished Sema3A binding, and Plexin-A4 ${ }^{-1-}$ mice (Gu et al., 2003; Tran et al., 2009). In addition, PTP $\delta$ physically interacts with NRP1 in mice brains (Fig. $2 F$ ). Thus, PTP $\delta$ may act as a major signaling mediator of Sema3A-regulated basal dendritic growth of cortical pyramidal neurons.

A rescue experiment showed that the catalytic activity of PTP $\delta$ is required for Sema3A-signaling (Fig. $3 B, C$ ). Immunoblotting analysis of $P t p \delta^{-/-}$brains suggested that PTP $\delta$ dephosphorylates the C-terminal regulatory tyrosine residue Y527 of Fyn and the related kinase Src in vivo (Fig. $6 A-C$ ). This dephosphorylation breaks the interaction between the $\mathrm{N}$-terminal $\mathrm{SH} 2$ and the C-terminal domain, allowing the activation of the kinase (Roskoski, 2005; Chaudhary et al., 2015). In primary cultured neurons, Sema3A-stimulation led to the dephosphorylation of Y527 in the DRG growth cones as well as in the cortical dendrites from wild-type but not from $P t p \delta^{-1-}$ (Figs. $6 D, E, 7 A, B$ ). As our earlier observation showed that Sema3A induces the dendritic branching of primary cultured cortical neurons through Fynactivation (Morita et al., 2006), PTP $\delta$ may activate Fyn and Src by the C-terminal dephosphorylation in Sema3A-signaling. This is further supported by the genetic interaction of $P t p \delta$ and Fyn in the basal dendritic growth of cortical neurons in vivo (Fig. $7 C-G$ ). As $P t p \delta^{-l-}, F_{y n}{ }^{-I-}$, and $P t p \delta^{+/-} ; F_{y n}{ }^{+/-}$showed the similar phenotype to Sema3a $a^{-1-}, \operatorname{PTP} \delta$, and Fyn may form a signaling axis to mediate Sema3A-induced cortical dendritic growth.

Fyn activates cyclin-dependent kinase 5 (Cdk5) by phosphorylation (Sasaki et al., 2002), which subsequently phosphorylates CRMP1 and CRMP2, the downstream molecules of Sema3Aintracellular signaling (Brown et al., 2004; Uchida et al., 2005; Cole et al., 2006). Because Crmpl ${ }^{-1-}$ and Sema3a ${ }^{+/-}$; $\mathrm{Crmp1}^{+/-}$mutants also show less elaborate cortical basal dendrites (Yamashita et al., 2007; Makihara et al., 2016), PTP $\delta$ may regulate CRMP1 via Fyn-Cdk5 phosphorylation cascade. Other kinases, such as focal adhesion kinase, MAPK, and thousandand-one-amino acid kinase 2 (TAOK2), have been shown to be involved in Sema3A-signaling and dendritic growth (Bechara et al., 2008; Schlomann et al., 2009; de Anda et al., 2012). As the overexpression of TAOK2 in $N p n-1^{\text {sema- }}$ restores the arborization of cortical basal dendrites (de Anda et al., 2012), investigation of PTP $\delta$ and TAOK2 relation would be of interest in the future.

Because several proteins were hyperphosphorylated in $P t p \delta^{-l-}$ brains (Fig. 6A), PTP $\delta$ may catalyze multiple proteins other than Fyn and Src in Sema3A signaling. Mitchell et al. (2016) recently reported the phosphoproteomic analysis of $C$. elegans ptp-3 (RB1878) mutant, which contains a premature stop codon before the phosphatase domain. Interestingly, several proteins, such as Cdk5, FER and MAPK, which have been shown to be involved in Sema3A signaling (Mitsui et al., 2002; Sasaki et al., 2002; Bechara et al., 2008), are hyperphosphorylated in the $p t p-3$ mutant (Mitchell et al., 2016). PTP-3 may dephosphorylate these activated kinases to facilitate the turnover of phosphorylationmediated intracellular signaling. Combination of phosphoproteomic analysis of $\operatorname{Ptp} \delta^{-1-}$ specimens and live-imaging of identified PTP $\delta$ substrates in cultured neurons would further reveal the role of PTP $\delta$ in Sema3A-mediated dendritic growth.

In conclusion, we demonstrate that the involvement of LAR class PTPs in soluble Semaphorin signaling is widely conserved in both nematodes and mammals. Whereas invertebrate PTP-3 is involved in Sema2A-regualted axon-guidance, vertebrate PTP $\delta$ contributes to Sema3A-induced cortical dendritic growth in vivo. These PTPs mediate the signaling through their enzymatic activity. In mammalian neurons, Fyn is a major downstream molecule of PTP $\delta$. It has been shown that presynaptic LAR class PTPs interact with postsynaptic ligands, including IL1RAPL1 and Slitrk, to mediate synapse formation (Yoshida et al., 2011; Takahashi and Craig, 2013; Um and Ko, 2013). Heparan sulfate proteoglycan Glypican-4 also binds PTP $\sigma$ to maintain excitatory synapse development (Ko et al., 2015). In addition, PTP $\sigma$ and LAR mediate the inhibitory action of chondroitin-sulfate proteoglycans in the injured CNS (Shen et al., 2009; Fisher et al., 2011). Together, PTP $\delta$ and its two related PTPs may serve as hub proteins to integrate multiple different extracellular cues in axonguidance, dendritic growth, synapse formation, and nerveregeneration. Revealing the crosstalk between Semaphorins and other extracellular ligands of LAR class PTPs would provide further insights into neural network formation and maintenance.

\section{References}

Ackley BD, Harrington RJ, Hudson ML, Williams L, Kenyon CJ, Chisholm $\mathrm{AD}$, Jin $\mathrm{Y}$ (2005) The two isoforms of the Caenorhabditis elegans leukocyte-common antigen related receptor tyrosine phosphatase PTP-3 function independently in axon guidance and synapse formation. J Neurosci 25:7517-7528. CrossRef Medline

Aricescu AR, McKinnell IW, Halfter W, Stoker AW (2002) Heparan sulfate proteoglycans are ligands for receptor protein tyrosine phosphatase sigma. Mol Cell Biol 22:1881-1892. CrossRef Medline

Bechara A, Nawabi H, Moret F, Yaron A, Weaver E, Bozon M, Abouzid K, Guan JL, Tessier-Lavigne M, Lemmon V, Castellani V (2008) FAKMAPK-dependent adhesion disassembly downstream of L1 contributes to semaphorin3A-induced collapse. EMBO J 27:1549-1562. CrossRef Medline

Brown M, Jacobs T, Eickholt B, Ferrari G, Teo M, Monfries C, Qi RZ, Leung T, Lim L, Hall C (2004) $\alpha 2$-Chimaerin, cyclin-dependent kinase 5/p35, and its target collapsin response mediator protein-2 are essential components in semaphorin 3A-induced growth-cone collapse. J Neurosci 24: 8994-9004. CrossRef Medline

Castellani V, Chédotal A, Schachner M, Faivre-Sarrailh C, Rougon G (2000) Analysis of the L1-deficient mouse phenotype reveals cross-talk between Sema3A and L1 signaling pathways in axonal guidance. Neuron 27:237249. CrossRef Medline

Chagnon MJ, Uetani N, Tremblay ML (2004) Functional significance of the LAR receptor protein tyrosine phosphatase family in development and diseases. Biochem Cell Biol 82:664-675. CrossRef Medline

Chaudhary F, Lucito R, Tonks NK (2015) Missing-in-metastasis regulates cell motility and invasion via PTP $\delta$-mediated changes in SRC activity. Biochem J 465:89-101. CrossRef Medline

Chédotal A, Del Rio JA, Ruiz M, He Z, Borrell V, de Castro F, Ezan F, Goodman CS, Tessier-Lavigne M, Sotelo C, Soriano E (1998) Semaphorins III and IV repel hippocampal axons via two distinct receptors. Development 125:4313-4323. Medline

Chin-Sang ID, Moseley SL, Ding M, Harrington RJ, George SE, Chisholm AD (2002) The divergent C. elegans ephrin EFN-4 functions in embryonic morphogenesis in a pathway independent of the VAB-1 Eph receptor. Development 129:5499-5510. CrossRef Medline

Cole AR, Causeret F, Yadirgi G, Hastie CJ, McLauchlan H, McManus EJ, Hernández F, Eickholt BJ, Nikolic M, Sutherland C (2006) Distinct priming kinases contribute to differential regulation of collapsin response mediator proteins by glycogen synthase kinase-3 in vivo. J Biol Chem 281:16591-16598. CrossRef Medline

de Anda FC, Rosario AL, Durak O, Tran T, Gräff J, Meletis K, Rei D, Soda T, Madabhushi R, Ginty DD, Kolodkin AL, Tsai LH (2012) Autism spectrum disorder susceptibility gene TAOK2 affects basal dendrite formation in the neocortex. Nat Neurosci 15:1022-1031. CrossRef Medline

Ensslen-Craig SE, Brady-Kalnay SM (2004) Receptor protein tyrosine phosphatases regulate neural development and axon guidance. Dev Biol 275: 12-22. CrossRef Medline 
Feng G, Mellor RH, Bernstein M, Keller-Peck C, Nguyen QT, Wallace M, Nerbonne JM, Lichtman JW, Sanes JR (2000) Imaging neuronal subsets in transgenic mice expressing multiple spectral variants of GFP. Neuron 28:41-51. CrossRef Medline

Fenstermaker V, Chen Y, Ghosh A, Yuste R (2004) Regulation of dendritic length and branching by semaphorin 3A. J Neurobiol 58:403-412. CrossRef Medline

Fisher D, Xing B, Dill J, Li H, Hoang HH, Zhao Z, Yang XL, Bachoo R, Cannon S, Longo FM, Sheng M, Silver J, Li S (2011) Leukocyte common antigen-related phosphatase is a functional receptor for chondroitin sulfate proteoglycan axon growth inhibitors. J Neurosci 31:14051-14066. CrossRef Medline

Fox AN, Zinn K (2005) The heparan sulfate proteoglycan syndecan is an in vivo ligand for the Drosophila LAR receptor tyrosine phosphatase. Curr Biol 15:1701-1711. CrossRef Medline

Gu C, Rodriguez ER, Reimert DV, Shu T, Fritzsch B, Richards LJ, Kolodkin AL, Ginty DD (2003) Neuropilin-1 conveys semaphorin and VEGF signaling during neural and cardiovascular development. Dev Cell 5:45-57. CrossRef Medline

Harrington RJ, Gutch MJ, Hengartner MO, Tonks NK, Chisholm AD (2002) The C. elegans LAR-like receptor tyrosine phosphatase PTP-3 and the VAB-1 Eph receptor tyrosine kinase have partly redundant functions in morphogenesis. Development 129:2141-2153. Medline

Johnson KG, McKinnell IW, Stoker AW, Holt CE (2001) Receptor protein tyrosine phosphatases regulate retinal ganglion cell axon outgrowth in the developing Xenopus visual system. J Neurobiol 49:99-117. CrossRef Medline

Johnson KG, Tenney AP, Ghose A, Duckworth AM, Higashi ME, Parfitt K, Marcu O, Heslip TR, Marsh JL, Schwarz TL, Flanagan JG, Van Vactor D (2006) The HSPGs Syndecan and Dallylike bind the receptor phosphatase LAR and exert distinct effects on synaptic development. Neuron 49:517-531. CrossRef Medline

Ko JS, Pramanik G, Um JW, Shim JS, Lee D, Kim KH, Chung GY, Condomitti G, Kim HM, Kim H, de Wit J, Park KS, Tabuchi K, Ko J (2015) PTPsigma functions as a presynaptic receptor for the glypican-4/LRRTM4 complex and is essential for excitatory synaptic transmission. Proc Natl Acad Sci U S A 112:1874-1879. CrossRef Medline

Ledig MM, Haj F, Bixby JL, Stoker AW, Mueller BK (1999) The receptor tyrosine phosphatase CRYPalpha promotes intraretinal axon growth. J Cell Biol 147:375-388. CrossRef Medline

Makihara H, Nakai S, Ohkubo W, Yamashita N, Nakamura F, Kiyonari H, Shioi G, Jitsuki-Takahashi A, Nakamura H, Tanaka F, Akase T, Kolattukudy P, Goshima Y (2016) CRMP1 and CRMP2 have synergistic but distinct roles in dendritic development. Genes Cells 21:994-1005. CrossRef Medline

Matthes DJ, Sink H, Kolodkin AL, Goodman CS (1995) Semaphorin II can function as a selective inhibitor of specific synaptic arborizations. Cell 81:631-639. CrossRef Medline

Meller K, Breipohl W, Glees P (1968) Synaptic organization of the molecular and the outer granular layer in the motor cortex in the white mouse during postnatal development: a Golgi- and electronmicroscopical study. Z Zellforsch Mikrosk Anat 92:217-231. CrossRef Medline

Minkwitz HG, Holz L (1975) The ontogenetic development of pyramidal neurons in the hippocampus (CAl) of the rat (in German). J Hirnforsch 16:37-54. Medline

Mitchell CJ, Kim MS, Zhong J, Nirujogi RS, Bose AK, Pandey A (2016) Unbiased identification of substrates of protein tyrosine phosphatase ptp-3 in C. elegans. Mol Oncol 10:910-920. CrossRef Medline

Mitsui N, Inatome R, Takahashi S, Goshima Y, Yamamura H, Yanagi S (2002) Involvement of Fes/Fps tyrosine kinase in semaphorin3A signaling. EMBO J 21:3274-3285. CrossRef Medline

Mizuno K, Hasegawa K, Katagiri T, Ogimoto M, Ichikawa T, Yakura H (1993) MPTP $\delta$, a putative murine homolog of HPTP $\delta$, is expressed in specialized regions of the brain and in the B-cell lineage. Mol Cell Biol 13:5513-5523. CrossRef Medline

Morita A, Yamashita N, Sasaki Y, Uchida Y, Nakajima O, Nakamura F, Yagi T, Taniguchi M, Usui H, Katoh-Semba R, Takei K, Goshima Y (2006) Regulation of dendritic branching and spine maturation by semaphorin3AFyn signaling. J Neurosci 26:2971-2980. CrossRef Medline

Nakamura F, Ugajin K, Yamashita N, Okada T, Uchida Y, Taniguchi M, Ohshima T, Goshima Y (2009) Increased proximal bifurcation of CA1 pyramidal apical dendrites in sema3A mutant mice. J Comp Neurol 516: 360-375. CrossRef Medline

Nakamura F, Kumeta K, Hida T, Isono T, Nakayama Y, Kuramata-Matsuoka E, Yamashita N, Uchida Y, Ogura K, Gengyo-Ando K, Mitani S, Ogino T, Goshima Y (2014) Amino- and carboxyl-terminal domains of Filamin-A interact with CRMP1 to mediate Sema3A signalling. Nat Commun 5:5325. CrossRef Medline

Nakao F, Hudson ML, Suzuki M, Peckler Z, Kurokawa R, Liu Z, GengyoAndo K, Nukazuka A, Fujii T, Suto F, Shibata Y, Shioi G, Fujisawa H, Mitani S, Chisholm AD, Takagi S (2007) The PLEXIN PLX-2 and the ephrin EFN-4 have distinct roles in MAB-20/semaphorin 2A signaling in Caenorhabditis elegans morphogenesis. Genetics 176:1591-1607. CrossRef Medline

Pasterkamp RJ (2012) Getting neural circuits into shape with semaphorins. Nat Rev Neurosci 13:605-618. CrossRef Medline

Pozas E, Pascual M, Nguyen Ba-Charvet KT, Guijarro P, Sotelo C, Chédotal A, Del Río JA, Soriano E (2001) Age-dependent effects of secreted semaphorins $3 \mathrm{~A}, 3 \mathrm{~F}$, and $3 \mathrm{E}$ on developing hippocampal axons: in vitro effects and phenotype of semaphorin 3A (-/-) mice. Mol Cell Neurosci 18:2643. CrossRef Medline

Raper JA (2000) Semaphorins and their receptors in vertebrates and invertebrates. Curr Opin Neurobiol 10:88-94. CrossRef Medline

Rashid-Doubell F, McKinnell I, Aricescu AR, Sajnani G, Stoker A (2002) Chick PTP $\sigma$ regulates the targeting of retinal axons within the optic tectum. J Neurosci 22:5024-5033. Medline

Roskoski R Jr (2005) Src kinase regulation by phosphorylation and dephosphorylation. Biochem Biophys Res Commun 331:1-14. CrossRef Medline

Roy PJ, Zheng H, Warren CE, Culotti JG (2000) mab-20 encodes semaphorin-2a and is required to prevent ectopic cell contacts during epidermal morphogenesis in Caenorhabditis elegans. Development 127: 755-767. Medline

Sasaki Y, Cheng C, Uchida Y, Nakajima O, Ohshima T, Yagi T, Taniguchi M, Nakayama T, Kishida R, Kudo Y, Ohno S, Nakamura F, Goshima Y (2002) Fyn and Cdk5 mediate semaphorin-3A signaling, which is involved in regulation of dendrite orientation in cerebral cortex. Neuron 35:907-920. CrossRef Medline

Schaapveld RQ, Schepens JT, Bächner D, Attema J, Wieringa B, Jap PH, Hendriks WJ (1998) Developmental expression of the cell adhesion molecule-like protein tyrosine phosphatases LAR, RPTP $\delta$ and RPTP $\sigma$ in the mouse. Mech Dev 77:59-62. CrossRef Medline

Schlomann U, Schwamborn JC, Müller M, Fässler R, Püschel AW (2009) The stimulation of dendrite growth by Sema3A requires integrin engagement and focal adhesion kinase. J Cell Sci 122:2034-2042. CrossRef Medline

Semaphorin Nomenclature Committee (1999) Unified nomenclature for the semaphorins/collapsins: Semaphorin Nomenclature Committee. Cell 97:551-552. CrossRef Medline

Shen Y, Tenney AP, Busch SA, Horn KP, Cuascut FX, Liu K, He Z, Silver J, Flanagan JG (2009) PTP $\sigma$ is a receptor for chondroitin sulfate proteoglycan, an inhibitor of neural regeneration. Science 326:592-596. CrossRef Medline

Shishikura M, Nakamura F, Yamashita N, Uetani N, Iwakura Y, Goshima Y (2016) Expression of receptor protein tyrosine phosphatase $\delta, \operatorname{PTP} \delta$, in mouse central nervous system. Brain Res 1642:244-254. CrossRef Medline

Sholl DA (1953) Dendritic organization in the neurons of the visual and motor cortices of the cat. J Anat 87:387-406. Medline

Sommer L, Rao M, Anderson DJ (1997) RPTP $\delta$ and the novel protein tyrosine phosphatase RPTP $\psi$ are expressed in restricted regions of the developing central nervous system. Dev Dyn 208:48-61. CrossRef Medline

Stepanek L, Stoker AW, Stoeckli E, Bixby JL (2005) Receptor tyrosine phosphatases guide vertebrate motor axons during development. J Neurosci 25:3813-3823. CrossRef Medline

Steup A, Ninnemann O, Savaskan NE, Nitsch R, Püschel AW, Skutella T (1999) Semaphorin D acts as a repulsive factor for entorhinal and hippocampal neurons. Eur J Neurosci 11:729-734. CrossRef Medline

Stoker AW (2015) RPTPs in axons, synapses and neurology. Semin Cell Dev Biol 37:90-97. CrossRef Medline

Supèr H, Soriano E (1994) The organization of the embryonic and early postnatal murine hippocampus. II. Development of entorhinal, commis- 
sural, and septal connections studied with the lipophilic tracer DiI. J Comp Neurol 344:101-120. CrossRef Medline

Takahashi H, Craig AM (2013) Protein tyrosine phosphatases PTP $\delta$, PTP $\sigma$, and LAR: presynaptic hubs for synapse organization. Trends Neurosci 36:522-534. CrossRef Medline

Takahashi H, Katayama K, Sohya K, Miyamoto H, Prasad T, Matsumoto Y, Ota M, Yasuda H, Tsumoto T, Aruga J, Craig AM (2012) Selective control of inhibitory synapse development by Slitrk3-PTPdelta transsynaptic interaction. Nat Neurosci 15:389-398. CrossRef Medline

Takahashi T, Fournier A, Nakamura F, Wang LH, Murakami Y, Kalb RG, Fujisawa H, Strittmatter SM (1999) Plexin-neuropilin-1 complexes form functional semaphorin-3A receptors. Cell 99:59-69. CrossRef Medline

Tamagnone L, Artigiani S, Chen H, He Z, Ming GI, Song H, Chedotal A, Winberg ML, Goodman CS, Poo M, Tessier-Lavigne M, Comoglio PM (1999) Plexins are a large family of receptors for transmembrane, secreted, and GPI-anchored semaphorins in vertebrates. Cell 99:71-80. CrossRef Medline

Taniguchi M, Yuasa S, Fujisawa H, Naruse I, Saga S, Mishina M, Yagi T (1997) Disruption of semaphorin III/D gene causes severe abnormality in peripheral nerve projection. Neuron 19:519-530. CrossRef Medline

Tran TS, Rubio ME, Clem RL, Johnson D, Case L, Tessier-Lavigne M, Huganir RL, Ginty DD, Kolodkin AL (2009) Secreted semaphorins control spine distribution and morphogenesis in the postnatal CNS. Nature 462:1065-1069. CrossRef Medline

Uchida Y, Ohshima T, Sasaki Y, Suzuki H, Yanai S, Yamashita N, Nakamura F, Takei K, Ihara Y, Mikoshiba K, Kolattukudy P, Honnorat J, Goshima Y (2005) Semaphorin3A signalling is mediated via sequential Cdk5 and GSK3beta phosphorylation of CRMP2: implication of common phosphorylating mechanism underlying axon guidance and Alzheimer's disease. Genes Cells 10:165-179. CrossRef Medline
Uetani N, Kato K, Ogura H, Mizuno K, Kawano K, Mikoshiba K, Yakura H, Asano M, Iwakura Y (2000) Impaired learning with enhanced hippocampal long-term potentiation in PTP $\delta$-deficient mice. EMBO J 19: 2775-2785. CrossRef Medline

Um JW, Ko J (2013) LAR-RPTPs: synaptic adhesion molecules that shape synapse development. Trends Cell Biol 23:465-475. CrossRef Medline

Valnegri P, Puram SV, Bonni A (2015) Regulation of dendrite morphogenesis by extrinsic cues. Trends Neurosci 38:439-447. CrossRef Medline

Wang F, Wolfson SN, Gharib A, Sagasti A (2012) LAR receptor tyrosine phosphatases and HSPGs guide peripheral sensory axons to the skin. Curr Biol 22:373-382. CrossRef Medline

Wang X, Zhang W, Cheever T, Schwarz V, Opperman K, Hutter H, Koepp D, Chen L (2008) The C. elegans L1CAM homologue LAD-2 functions as a coreceptor in MAB-20/Sema2 mediated axon guidance. J Cell Biol 180: 233-246. CrossRef Medline

Winberg ML, Mitchell KJ, Goodman CS (1998) Genetic analysis of the mechanisms controlling target selection: complementary and combinatorial functions of netrins, semaphorins, and IgCAMs. Cell 93:581-591. CrossRef Medline

Worzfeld T, Offermanns S (2014) Semaphorins and plexins as therapeutic targets. Nat Rev Drug Discov 13:603-621. CrossRef Medline

Yamashita N, Morita A, Uchida Y, Nakamura F, Usui H, Ohshima T, Taniguchi M, Honnorat J, Thomasset N, Takei K, Takahashi T, Kolattukudy P, Goshima Y (2007) Regulation of spine development by semaphorin3A through cyclin-dependent kinase 5 phosphorylation of collapsin response mediator protein 1. J Neurosci 27:12546-12554. CrossRef Medline

Yoshida T, Yasumura M, Uemura T, Lee SJ, Ra M, Taguchi R, Iwakura Y, Mishina M (2011) IL-1 receptor accessory protein-like 1 associated with mental retardation and autism mediates synapse formation by transsynaptic interaction with protein tyrosine phosphatase delta. J Neurosci 31:13485-13499. CrossRef Medline 